\title{
VOLATILITY AND DIVERSIFICATION OF EXPORTS: FIRM-LEVEL THEORY AND EVIDENCE
}

\author{
Gonzague Vannoorenberghe ${ }^{a, b, *}$, Zheng Wang ${ }^{c, d}$, Zhihong Yu ${ }^{d, e, f}$ \\ ${ }^{a}$ IRES, Université Catholique de Louvain, Belgium \\ ${ }^{b}$ CentER, Tilburg University, Netherlands \\ ${ }^{c}$ Hull University Business School, UK \\ ${ }^{d}$ GEP, University of Nottingham, UK \\ ${ }^{e}$ Institute of World Economy (IWE), Fudan University, China \\ ${ }^{f}$ CESifo, Germany
}

July 1,2016

\begin{abstract}
We show using detailed firm-level Chinese data that, among small exporters, firms selling to a more diversified set of countries have more volatile exports, while the opposite holds among large exporters. This a priori surprising result for small firms is robust to a wide array of specifications and controls. Our theoretical explanation for these observations rests on the presence of fixed costs of exports per destination and short-run demand shocks. In this setup, the volatility of a firm's exports depends not only on the diversification of its destination portfolio but also on whether it exports permanently to all markets. Among small exporters, a more diversified pool of destinations makes the firm more likely to export occasionally to some markets, thereby raising export volatility.
\end{abstract}

Key Words: Volatility, diversification, exports

\section{JEL Classifications: F1}

\section{Acknowledgments}

The authors are particularly grateful to the anonymous referees, the associate editor, and to Theo Eicher (the editor) for their comments, as well as seminar participants at Renmin University, Luzern University, KU Leuven and at the GEP of Nottingham University for valuable suggestions. All errors are our own.

\footnotetext{
${ }^{*}$ Corresponding author. Email addresses: gonzague.vannoorenberghe@uclouvain.be (G. Vannoorenberghe), z. wang@hull.ac.uk (Z. Wang), zhihong · yu@nottingham.ac.uk (Z. Yu).
} 


\section{Introduction}

Exporting is a risky business. Selling on foreign markets exposes a firm to sources of risk - such as exchange rate fluctuations or trade policy changes - that it does not face at home. Imperfect knowledge of local conditions may also leave exporters more vulnerable to cost or demand shocks in foreign markets. A number of studies suggest that exports are more volatile than domestic sales (Vannoorenberghe, 2012) and that openness to trade — at least in some cases — raises the volatility of output at the level of sectors (di Giovanni and Levchenko, 2009) or countries (Rodrik, 1998), a particularly sensitive topic for developing countries (UN, 2011).

Although selling to a foreign market may be risky, firms can export to more than one destination. If shocks to these destinations are imperfectly correlated, exports should appear relatively stable from the standard diversification effect of portfolio theory. So do firms with more diversified exports across countries really have more stable exports? Our answer, based on a large sample of Chinese exporters, is no, or at least not unconditionally. While the expected relationship holds for firms with large exports, we show that, for small exporters, a more diversified pool of destinations is associated with a higher export volatility.

Observing such patterns among Chinese exporters is of particular interest as China is usually seen as a flagship of export-led development. Over the 2000-2006 period, Chinese exports grew annually by $20 \%$ and national export growth accounted for over $3 / 4$ of the variance of GDP growth, ${ }^{1}$ making a focus on the volatility of exports warranted in the case of China. Without questioning the benefits of export diversification for development, our study suggests that inducing small firms to split their exports among more markets may have the unintended consequence of raising their export volatility, with potentially negative effects on long-run performance. ${ }^{2}$ While exporting to more markets may of course benefit small firms if it raises their expected profits, we stress that diversifying sales across markets with the sole aim of reducing export volatility may be a misleading strategy for small firms. The usual recommendation for developing countries to diversify exports, although well studied at the macro level (e.g. Haddad et al. (2013), UN (2011)), may thus not simply carry over to all firms at the micro level.

\footnotetext{
${ }^{1}$ To compute this number, we define $Y$ as GDP, $X$ as exports, and $D=Y-X$ as other components of GDP, and $g^{Y} \equiv \Delta Y / Y$, $g^{X} \equiv \Delta X / Y$, and $g^{D} \equiv \Delta D / Y$. Following Kramarz et al. (2015), the contribution of export growth to the variance of GDP growth is computed as $\left[\operatorname{VAR}\left(g^{X}\right)+2 \frac{\operatorname{VAR}\left(g^{X}\right) \operatorname{COV}\left(g^{X}, g^{D}\right)}{\operatorname{VAR}\left(g^{X}\right)+\operatorname{VAR}\left(g^{D}\right.}\right] / \operatorname{VAR}\left(g^{Y}\right)$.

${ }^{2} \mathrm{See}$, for example, Juvenal and Monteiro (2013) on the negative link between volatility and productivity.
} 
Our proposed explanation rests on two assumptions: (i) short-run demand on each market is firmspecific, stochastic, and imperfectly correlated across markets, and (ii) firms must pay a fixed cost per country to which they export. ${ }^{3}$ In this setup, a firm only exports to a particular market in a given year if the realization of demand is high enough to cover the fixed costs. To make the intuition transparent, assume that there are only two export markets, $\mathrm{A}$ and $\mathrm{B}$, that the firm sells more to $\mathrm{A}$ than to $\mathrm{B},{ }^{4}$ and consider two cases. First, if demand is such that selling each year in both markets is profitable, a firm with a less concentrated export portfolio, i.e. with slightly higher sales on B and lower sales on A, would be less sensitive to destination-specific shocks and the volatility of its exports would be lower (diversification effect). Second, if a bad realization of demand in B does not allow to cover the fixed costs, exports to B fluctuate between positive values and zero, making them relatively volatile. In that case, a firm with a less concentrated export profile, i.e. with slightly higher sales in B and lower sales in A, sells a higher fraction of its exports to a market where it has relatively volatile sales (composition effect). These two effects imply that the net impact of a more diversified destination portfolio on export volatility is ambiguous and can be positive if the composition effect dominates the diversification effect. We show that the relative size of the two effects depends on the firm's size. The larger the exporter, the more likely it sells continuously to both markets. When comparing two large exporters with different Herfindahl indices, the diversification effect should therefore dominate the composition effect, generating a positive link between the Herfindahl index and volatility. Among small exporters, however, the likelihood of selling occasionally to B is relatively large, implying that the composition effect can dominate the diversification effect. In that case, a more diversified portfolio of destinations is associated with a higher volatility of exports among small exporters.

Our empirical analysis uses customs data on the universe of Chinese exporting firms from 2000 to 2006, matched with detailed balance sheet data from the Annual Survey of Industrial Firms. We show that the variance of a firm's export growth depends (i) negatively on its worldwide exports, (ii) negatively on the diversification of its export destination (Herfindahl index), and (iii) positively on the interaction between the two. These results, which are robust to a wide array of controls as well as to different measures of the main variables, are the basis for our claim. We also present evidence that the results are driven by the destinations to which firms only export occasionally, as suggested by our theory. We also test for different confounding factors, such as other sources of export dynamics (à la Albornoz et al.,

\footnotetext{
${ }^{3}$ These can also be interpreted as fixed costs of shipment. A recent literature (Alessandria et al., 2010; Hornok and Koren, 2015; Kropf and Sauré, 2014) has emphasized the importance of such costs, either through direct evidence or as a necessity to explain the lumpy shipment of goods to export markets.

${ }^{4}$ This may be due to country-specific preferences or to different market conditions (e.g. A is a larger country).
} 
2012) or other dimensions of diversification (product diversification) and show that these do not drive the results. We further provide some evidence, using an instrumental variable approach, that reverse causality is unlikely to drive our results. Our results also contribute to understanding the difference in volatility between firms of different sizes. We document the empirical regularity that smaller firms sell less frequently to their destination markets, thereby raising their measured export volatility compared to larger firms.

Firms can of course be diversified in other dimensions than in terms of destinations. Exporters could for example have a diversified bundle of products or a diversified set of destination-product pairs. We show throughout that most of the patterns that we observe for the diversification across destinations also hold for these other dimensions. Exporters with a more diversified portfolio of exported products appear less volatile than less diversified exporters if they are large enough, and this result is typically reversed among small exporters. It is conceivable that a similar mechanism to the one we propose is at play on the product dimension if there are fixed costs of exports per product (e.g. providing quality tests each year that a product is exported, updating packaging information, etc.). We however focus most of our analysis on export diversification across destinations because our results are slightly more robust in that dimension. To simplify the exposition, we only report some of the core results on the product dimension in the main text but a large array of results on the product and product-destination dimensions are available in the Appendix.

This paper contributes to the large literature which examines the link between international trade and the volatility of economic activity. The question - mostly addressed from a macroeconomic perspective — has received renewed attention after a stream of works showing that macroeconomic volatility has detrimental effects on growth (Ramey and Ramey, 1995) or development (Koren and Tenreyro, 2007). Early theoretical arguments by Newbery and Stiglitz (1984) recognize that international trade, by increasing volatility, may reduce welfare and a number of studies has examined the link between trade and volatility at the country or sector level (e.g. Rodrik, 1998; Easterly et al., 2001; Bejan, 2006; di Giovanni and Levchenko, 2009). Caselli et al. (2014) show that, at the macroeconomic level, the diversification of sales across countries made possible by international trade can act as a source of stability. ${ }^{5}$

At the level of firms, the idea that export diversification across countries should stabilize exports is not

\footnotetext{
${ }^{5}$ Note that our analysis is not inconsistent with these results as the positive link between diversification and volatility across small exporters has no direct implications for the aggregate relationship.
} 
new but there is only scant research on the topic. A classical paper by Hirsch and Lev (1971) shows, based on a panel of 500 firms from the Netherlands, Denmark and Israel, that firms with more diversified exports have less volatile sales, in line with standard portfolio theory. A more recent study by Juvenal and Monteiro (2013) shows that the exports of Argentinian firms with more diversified exports are more stable. Since volatility can have a strong negative effects on firms and their development, a recent literature has looked at how diversification, through the implied decrease in volatility, can improve productivity (Juvenal and Monteiro, 2013), help to finance investment (Shaver, 2011) or improve profitability (Wagner, 2014). ${ }^{6}$

The rest of the paper is structured as follows. Section 2 describes the data and presents some preliminary empirical observations. Section 3 develops a simple theory that can explain the observed patterns and puts the link between volatility and diversification in perspective. Section 4 provides the main empirical results and a number of robustness checks and Section 5 concludes.

\section{Export Market Diversification and Volatility: A First Look at the Firm-level Data}

In this section we describe the data, provide the definition of the main variables and outline some preliminary facts on the link between the volatility of a firms' export sales and the diversification of its export destinations. Further exploration of the data and econometric evidence are presented in Section 4.

\subsection{Data}

We use detailed firm-level export transaction data from the Chinese Customs Trade Statistics (CCTS) Database maintained by the General Administration of Customs of China during the period of 20002006. All export transactions going through the Chinese customs from 1 January 2000 to 31 December 2006 are included. The value of this data set is mainly in the rich information it contains; most relevantly, it records firm identifier, dates of transaction, HS8 product code, value and quantity of goods, as well as the destination of exports. ${ }^{7}$ For the purpose of this study, we aggregate exports for each firm by year, product (HS8 level), and export destination. We only keep firms that export in all years of our sample to ensure that the volatility of exports is based on a large enough number of observations. ${ }^{8}$ We focus

\footnotetext{
${ }^{6}$ Baum et al. (2013) show that firms with more diversified export destinations invest more in R\&D, although their argument does not rely on the link with volatility.

${ }^{7}$ See Wang and Yu (2012) and Upward et al. (2013) for further details of the description of the data.

${ }^{8}$ It is common to use 5 data points as a minimum to compute volatility, see e.g. Buch et al. (2009b), Vannoorenberghe (2012), or Garcia-Vega et al. (2012) among others. As a robustness check, in Section 4.3 we constructed an alternative sample
} 
on production firms only, and exclude companies which serve as middlemen in trade from the sample. ${ }^{9}$ The resulting sample includes 23,822 firms, which contributed about $50 \%$ of China's total export sales during our sample period.

Since the Chinese customs data lack information on firms' production activities (e.g. employment, domestic sales or capital investment), we complement our analysis with a new dataset linking the customs transactions to firms' balance sheet information in the Annual Surveys of Industrial Firms (ASIF) of the National Bureau of Statistics (NBS) in China. The ASIF data include state-owned firms of all sizes and other firms with annual turnover exceeding 5 million yuan (equivalent to around 700 thousand U.S. dollars during that period) in the manufacturing sectors. We matched the observations in the CCTS customs data with those in the ASIF data using firm names and their key contact details such as postcode, legal person name, and telephone number as the identifier. ${ }^{10}$ This leaves us with a sample of 8,387 matched firms exporting continuously from 2000 to 2006, accounting for $55 \%$ of export sales in the customs sample.

\subsection{Volatility and diversification}

We define the volatility of firm $j$ 's exports over the period as the variance of the growth rate of its exports (see Vannoorenberghe, 2012; di Giovanni et al., 2014):

$$
\operatorname{Vol}_{j}=\sum_{t}\left(g_{j t}-\frac{1}{T} \sum_{t} g_{j t}\right)^{2}
$$

and define $g_{j t}$ as the mid-point growth rate (see Davis et al., 2006; Bricongne et al., 2012) of firm j's exports at $t\left(x_{j t}\right)$ :

$$
g_{j t}=\frac{x_{j t}-x_{j, t-1}}{\left(x_{j t}+x_{j, t-1}\right) / 2} .
$$

We choose the mid-point growth rate since it is has the advantage of being bounded and symmetric around zero, but our results are robust to using alternative definitions such as the log change in exports.

which also include firms that enter/exit exporting during the sample period. Our results are robust to using this extended sample.

${ }^{9}$ See Upward et al. (2013) for the procedures of how to identify these trading companies in the data we use.

${ }^{10}$ See Upward et al. (2013) for more details on the matching approaches. 
To measure export market diversification, we compute a firm-level Herfindahl index defined as:

$$
\operatorname{Herf}_{j}=\sum_{i=1}^{N_{j 0}} \frac{x_{j i 0}^{2}}{\left(\sum_{i=1}^{N_{j 0}} x_{j i 0}\right)^{2}},
$$

where $x_{j i 0}$ is the total value of exports from firm $j$ to country $i$ in year 2000 (the first year of our sample) and $N_{j 0}$ is the total number of (foreign) markets firm $j$ exports to in 2000. By definition, $\operatorname{Herf}_{j}$ is between zero and one, with lower values indicating higher degrees of export market diversification. In extreme cases, a Herfindahl of zero means an infinitely large number of destinations with each of them sharing an infinitely small fraction of exports, and a Herfindahl of one represents single-destination

exporters. We also compute a similar measure of diversification along the product dimension, $\operatorname{Her} f_{j}^{p}$ which is defined as $H e r f_{j}$ in (2) with $i$ referring to a product and $N_{j 0}$ being the number of HS6 products exported by firm $j$ in 2000 . The correlation between the two Herfindahl indices is 0.05 in our sample.

Table 1 provides extensive summary statistics of the key variables for the Chinese customs sample (CCTS) (Columns 1-9) and the matched sample (Columns 10-18) by firm size. These show quite some variation across firms with respect to export sales volatility and export market diversification. Larger exporters have on average less volatile exports and have a more diversified portfolio of destinations (lower Herfindahl index) than smaller exporters. Note that the variation in diversification is also reflected in other indicators than the Herfindahl index, such as the share of top export destination, and the number of export markets. On average, a firm exports to 7 markets, but the share is unevenly distributed with $70 \%$ of the export value going to the top destination. On the other hand, the characteristics of firms export destinations in terms of average income or of volatility of GDP growth are similar across firm sizes. Note that in comparison with the customs sample, the matched firms are on average larger (measured by export sales), slightly more volatile, and have more diversified export destinations. However, the two samples have similarly large standard deviations in all these variables, thus ensuring sufficient variations for econometric identification.

\subsection{Relationship between volatility, diversification, and firm size}

Before turning to a full-fledged econometric analysis of the link between export volatility and diversification, we provide a graphical account of this relationship at the firm-level in Figure 1, where we define diversification along the destination dimension. We plot the average volatility of firms in the CCTS sam- 


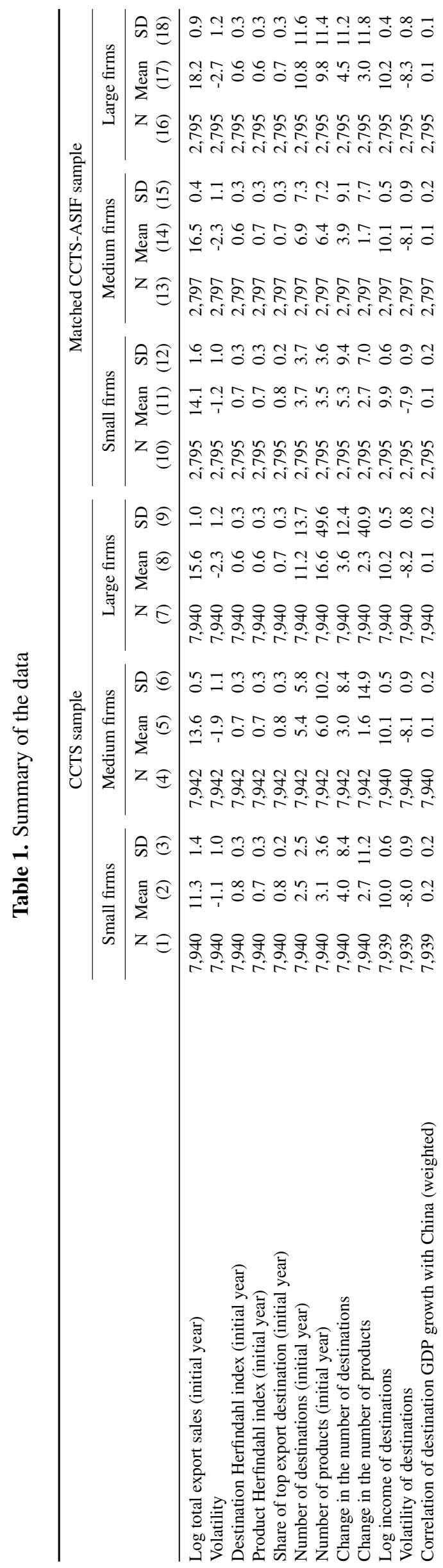

곡

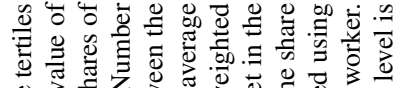

o

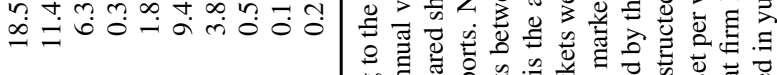

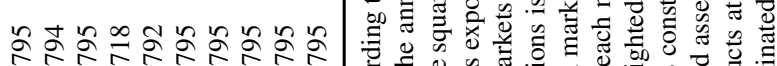

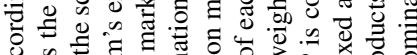

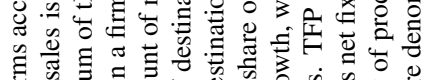

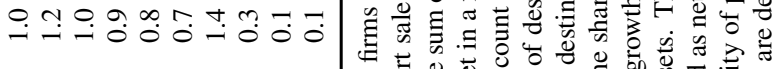

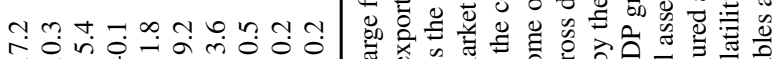

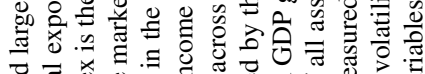

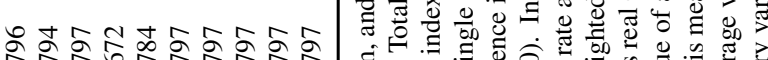

तंतोंत

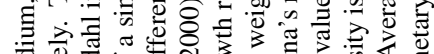

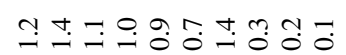

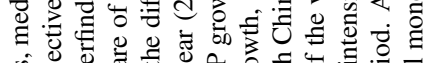

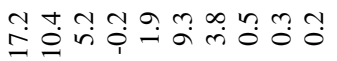

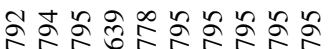

要

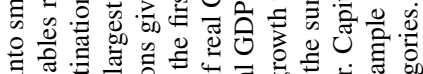

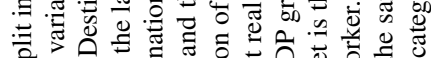

4ivicisidici

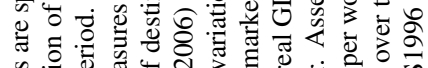

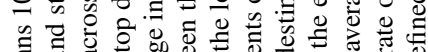

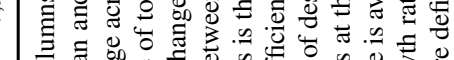

30

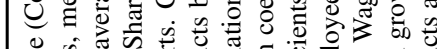

동ㄱำ

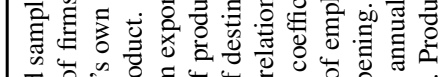

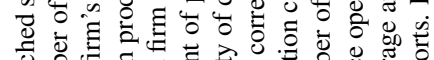

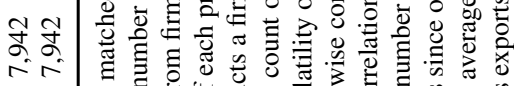

:०:

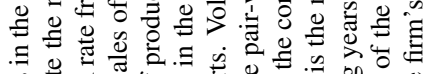

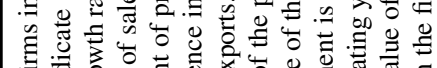

3숭

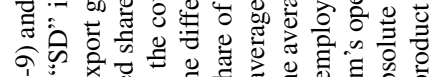

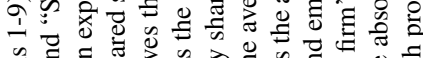

等

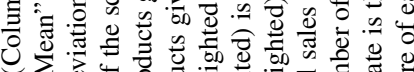

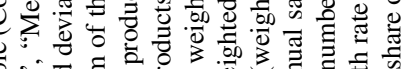

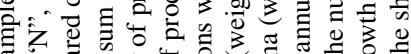



항ㅎㅁ

U व व

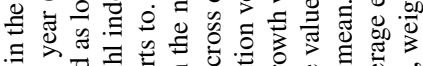

的可

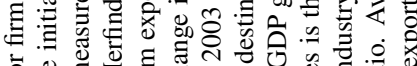

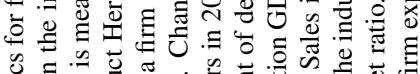

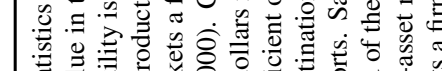

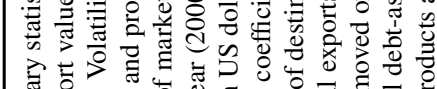

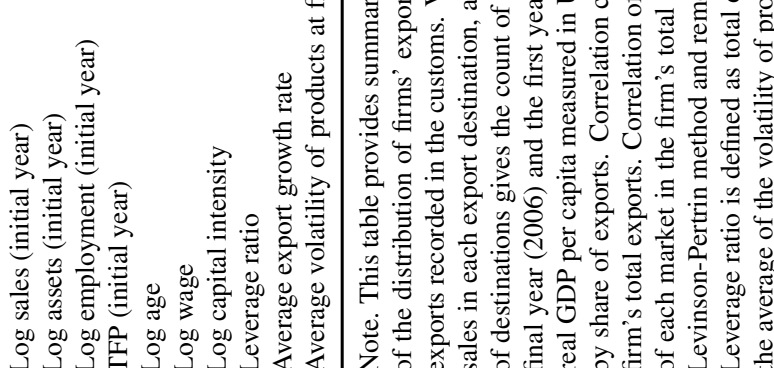


ple by decile of the Herfindahl index - with industry-province-ownership ${ }^{11}$ effects removed - for three size categories (defined as export sales): large, medium, and small. ${ }^{12}$ The most striking pattern emerging from Figure 1 is that the volatility-diversification relationship can be either positive or negative, depending on firms' size category. For large exporters (firms with large exports), volatility tends to decrease when the Herfindahl index declines, indicating that firms' export sales become less volatile when their export market profiles are more diversified (less concentrated). For small exporters, on the other hand, the volatility of exports monotonically increases when the Herfindahl index decreases, suggesting a positive association between diversification and volatility. For medium-sized exporters, volatility does not seem to vary by the degree of diversification. This indicates that the size of firms' exports plays a crucial role in the firm-level volatility-diversification relationship, which, to the best of our knowledge, has not been reported before in the literature. We will provide a more thorough econometric investigation of this relationship in Section 4.

It also appears from Figure 1 that small exporters exhibit higher degrees of export volatility than mediumsized exporters, which in turn have more volatile exports than large exporters. In other words, the volatility of exports is on average lower for larger exporters. As a consequence of this pattern, the volatility differential between the different size groups decreases with the level of concentration of exports (i.e. with the Herfindahl index) but remains significant for all values of the Herfindahl index. The result that firms exporting more have less volatile exports is in line with Vannoorenberghe (2012), who shows that the volatility of exports is decreasing in the export openness, and echoes the standard result that larger firms have less volatile sales (e.g. Buch et al., 2009a; Kelly et al., 2013) or employment (Kurz and Senses, 2016).

Figure A2 in the Appendix shows that the patterns obtained when using product diversification instead of destination diversification are less clear-cut. Again, larger exporters exhibit lower volatility, but the link between product diversification and export volatility seems less dependent on firm size. Our paper focuses on explaining the surprising patterns observed in Figure 1 and will in that sense concentrate on diversification across destinations. We show in the appendix that most of our results do carry over to using a Herfindahl index based on the share of different products or of different product-destination pairs in the firm's export.

\footnotetext{
${ }^{11}$ Ownership refers to whether the firm is state-owned, foreign-owned or a private domestically-owned firm.

${ }^{12}$ Firm size categories are defined according to the firm's export sales relative to the top and bottom third sales quantiles within corresponding industry-province-ownership cell.
} 


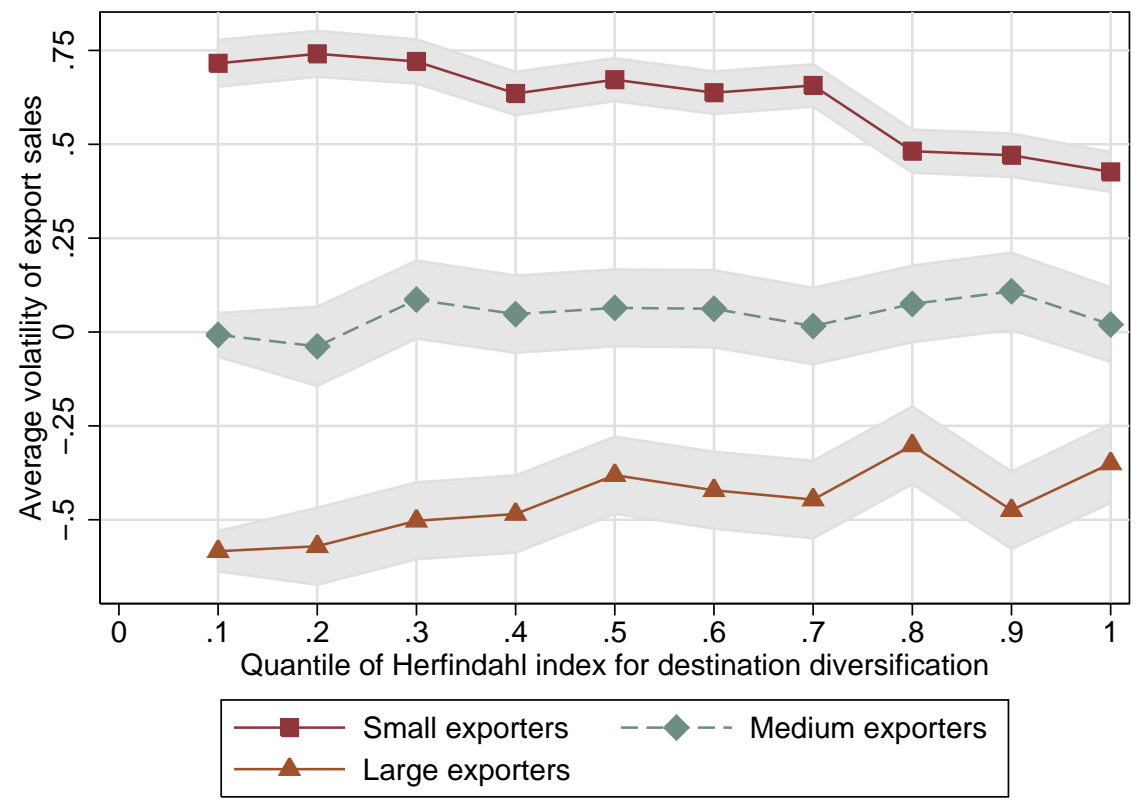

Figure 1. Volatility and destination diversification. Export volatility is measured as log of squared deviation in export growth rate from firm's own average. Quantiles of Herfindahl index is defined on the whole population of firms. Firm size category is defined according to the firm's exports (averaged over years) relative to the tertiles of its corresponding industry-province-ownership cell. Volatility and Herfindahl index are removed of industry, province, and ownership effects. Source: CCTS.

\section{Theory}

Before we turn to a detailed econometric analysis of the relationship between export size, diversification and volatility, the present section develops a stylized model helping to think about this relationship in a more systematic way. We show in the context of this model how the patterns observed in Figure 1 can arise. Although we concentrate on a model with two export markets for simplicity, we show in the Appendix using simulations that the reasoning extends to a setup with many countries.

\subsection{Setup}

We consider firms located in a Home country, which can export to two markets: market 1 and 2. Firms produce using exclusively labor at a wage normalized to one. Each firm draws a productivity parameter $\varphi$ which captures the units of output produced per unit of labor:

$$
y=\varphi l
$$


Firms, indexed by $j$, face an inverse demand function for their product in market $i \in\{1,2\}$ at time $t$ given by:

$$
p_{j i t}(q)=\left(\zeta_{j i t} \chi_{j i}\right)^{\frac{1}{\sigma}} q^{-\frac{1}{\sigma}}
$$

where $\sigma$ is the price elasticity of demand. The price that firm $j$ obtains depends on the quantity it sells and on two exogenous demand parameters. The first, $\chi_{j i}$, is time invariant and firm-specific and captures the long run differences in taste or market conditions faced by different firms on different markets. ${ }^{13}$ The second, $\zeta_{j i t}$, is a time-varying idiosyncratic shock to the demand for firm $j$ 's product on market $i$ at time $t$. For simplicity, we assume that the $\zeta_{j i t}$ are drawn independently from the same distribution across firms and markets:

$$
\zeta_{j i t}=\left\{\begin{array}{cc}
\bar{s} & \text { with probability } \frac{1}{2} \\
\underline{s} & \text { with probability } \frac{1}{2}
\end{array}\right.
$$

Selling on market $i$ requires the payment of a fixed cost of exporting $f$. For each destination, after the realization of the time-varying shock $\zeta_{j i t}$, firms decide (i) whether to export (i.e. whether to pay $f$ ) and (ii) what quantity to sell, taking into account the effect on the price. It is worth emphasizing that no decision is taken before the realization of shocks in this simple setup. Maximizing profits with respect to $q$ gives the optimal export sales of firm $j$ on market $i\left(x_{j i t}=p_{j i t} q_{j i t}\right)$ as a function of the demand shock:

$$
x_{j i t}= \begin{cases}\sigma \zeta_{j i t} \lambda_{j i} & \text { if } \zeta_{j i t} \lambda_{j i}>f \\ 0 & \text { otherwise }\end{cases}
$$

where $\lambda_{j i} \equiv(\sigma-1)^{\sigma-1} \sigma^{-\sigma} \chi_{j i} \varphi^{\sigma-1}$ is larger the more productive the firm and the higher the demand for its product on market $i$. A firm only exports to a market at time $t$ if the variable profits are sufficient to cover the fixed costs of export to that market.

It is worth emphasizing at this stage how our setup compares to the existing literature on the choice of export destinations by firms (e.g. Eaton et al., 2011, among others). As in this literature, our firms decide optimally on the set of destinations to which they export by comparing their variable profits to the fixed

\footnotetext{
${ }^{13}$ See Vannoorenberghe (2012). $\chi_{j i}$ consists of idiosyncratic shocks to the firm as well as of the price index in $i$ and the size of market $i$. We take a partial equilibrium perspective for simplicity and do not explicitly solve for the price index in each country. Doing so would have no effect on the analysis.
} 
costs of selling on a market. ${ }^{14}$ In our model, however, firms face short-run demand shocks on export markets, which leads some of them to export only occasionally to a destination ( $j$ exports occasionally to $i$ if $\left.\lambda_{j i \underline{s}}<f<\lambda_{j i} \bar{s}\right)$. Our analysis will therefore concentrate on the volatility of exports arising from demand shocks given the firms' choice of destinations to which they regularly (i.e. occasionally or permanently) export. ${ }^{15}$ We compare our perspective to the literature on short-lived export spells or sequential exporting (Besedes and Prusa, 2011; Albornoz et al., 2012), in which the set of markets to which a firm regularly exports changes, in Section 3.4.

\subsection{Measurement of volatility and diversification}

As is common in the literature on firm-level export volatility (see references in Section 2.2), we define the volatility of a firm $j$ 's exports as the variance of the mid-point growth rate of its exports $\left(V_{j}\right)$ :

$$
\begin{aligned}
g_{j t} & =\sum_{i=1,2} \omega_{j i t} g_{j i t} \\
V_{j} & =\operatorname{VAR}\left(g_{j t}\right)
\end{aligned}
$$

where $\omega_{j i t}$ is the weight of market $i$ in the sales of firm $j$ at $t$ and $t-1$, and where $g_{j i t}$ is the mid-point growth rate of firm $j$ on market $i$ between $t-1$ and $t$.

$$
g_{j i t}=2 \frac{x_{j i t}-x_{j i t-1}}{x_{j i t}+x_{j i t-1}} \quad, \quad \omega_{j i t}=\frac{x_{j i t}+x_{j i t-1}}{x_{j 1 t}+x_{j 1 t-1}+x_{j 2 t}+x_{j 2 t-1}} .
$$

Our empirical measure of volatility will be the variance of $g_{j t}$ as defined in (7). From a theory perspective, however, decomposing the variance of $g_{j t}$ is impractical since the weights on each market are varying over time. To keep the theory simple, we follow di Giovanni et al. (2014) and use the following approximation:

$$
g_{j t}=\sum_{i} \omega_{j i} g_{j i t},
$$

\footnotetext{
${ }^{14}$ Although firms take the demand parameter on each market as given in the current setup, our model easily extends to a case where firms perform a market-specific investment to raise the demand for their product $\left(\chi_{j i}\right)$ as in Arkolakis (2010). This additional margin endogenizes the level of exports on each market - and therefore the diversification of sales across markets but comes with substantial complexity for little additional insight.

${ }^{15}$ The long-term choice of destinations in which the firm exports - which is the one typically considered by the literature can be made more explicit by assuming that, at stage 0 , a firm pays a sunk cost of export $f_{e}$ to each market where it wants to export. The firm therefore "enters" a market and pays $f_{e}$ if the expected profits of selling on the market are sufficient to cover the sunk costs. The set of markets in which the firm is active in the long run is those markets where it paid $f_{e}$, while the markets where it actually sells in a given period are markets where $\zeta_{j i t} \lambda_{j i}>f$.
} 
where $\omega_{j i} \equiv x_{j i} / \sum x_{j m}$ is a time-invariant measure of the importance of market $i$ in the total exports of firm $j$. We discuss this measure at the end of the present section and are more explicit about the meaning of this approximation in the Theory Appendix. The volatility of firm j's exports can be approximated as:

$$
V_{j}=\sum_{i} \omega_{j i}^{2} V A R_{j i}
$$

where $V A R_{j i}$ is the variance of the growth rate of firm $j$ 's exports to $i$ and where we make use of the assumption that shocks to market 1 and 2 are uncorrelated. We show in the Appendix that a positive partial correlation between shocks on both markets, which would capture business cycle co-movements, would not affect any of the qualitative results. Markets 1 and 2 can also be thought of as two groups of countries among which demand shocks are perfectly correlated. We address these issues empirically in Section 4.3. The extent to which a firm $j$ 's exports are concentrated in a particular destination is captured by the Herfindahl index of exports, which we define as:

$$
\operatorname{Herf}_{j}=\sum_{i} \omega_{j i}^{2}
$$

It is immediate from (12) that, in our simple setup with two destinations, there is a one-to-one link between the share of sales to a given market $i\left(\omega_{j i}\right)$ and the Herfindahl index of export destinations.

The approximation above is silent about how to exactly define $\omega_{j i}$, the importance of market $i$ for firm $j$. Although this choice does not affect our empirical measure of volatility (the variance of actual growth rates), it matters for our empirical measure of diversification as we construct the Herfindahl index of exports using (12). For our baseline analysis, we follow di Giovanni et al. (2014) and use the market share at the beginning of the sample, i.e. $\omega_{j i}=x_{j i 0} / \sum_{m} x_{j m 0}$, which has the advantage that shocks over the period do not affect our measure of diversification. As described in Section 3.4.2, this is a useful property to avoid that our empirical results be driven by alternative channels and to tame down issues of reverse causality. We also show in the Appendix that a natural approximation would be $\omega_{j i}=$ $\sum_{t} x_{j i t} / \sum_{i, t} x_{j i t}$, i.e. the share of exports going to destination $i$ over all years. This measure is however more prone to other biases and we only use it as a robustness check in the empirical analysis. ${ }^{16}$

\footnotetext{
${ }^{16}$ To check the quality of our approximation in equation (11), we compute the correlation in our sample between the actual variance of $g_{j t}$ and the variance of $g_{j t}$ as defined in (11). It is 0.92 if we use $\omega_{j i}=x_{j i 0} / \sum_{m} x_{j m 0}$ and 0.95 if $\omega_{j i}=\sum_{t} x_{j i t} / \sum_{i, t} x_{j i t}$. The approximation of the variance that we use in the theory thus seems reasonably close to the empirical measure of volatility.
} 


\subsection{Effect of diversification on the volatility of exports}

Before turning to the exact implications of our model's assumptions, it is worth outlining the link between the Herfindahl index and the volatility of exports in a setup with two markets where the variance of a firm $j$ 's export growth on market $i$ can be a function of $x_{j i}$, the time-invariant approximation of its exports to $i$. Totally differentiating (11) and (12) with respect to $x_{j 1}$ and $x_{j 2}$, and defining $x_{j}=x_{j 1}+x_{j 2}$, shows that a change in the volatility of a firm's exports can be decomposed between the effect of the concentration of exports and the effect of total export size (derivation in the Appendix):

$$
d V_{j}=\frac{d H e r f_{j}}{2\left(x_{j 1}-x_{j 2}\right)}\left[\frac{\partial\left(x_{j 1}^{2} V A R_{j 1}\right)}{\partial x_{j 1}}-\frac{\partial\left(x_{j 2}^{2} V A R_{j 2}\right)}{\partial x_{j 2}}\right]+d x_{j}\left[\sum_{i=1,2} \omega_{j i}^{3} \frac{\partial V A R_{j i}}{\partial x_{j i}}\right] .
$$

The first part of equation (13) shows the role of the concentration of exports, captured by the Herfindahl index, on volatility. Consider two firms, $A$ and $B$, which have the same total exports $\left(x_{A}=x_{B}\right)$. Assume that they both sell more to market 1 than to market 2 and that firm $B$ has a marginally higher Herfindahl index than firm $A$, i.e. it sells relatively more to market 1 than firm $A$. Equation (13) states that firm $B$ has more volatile exports than firm $A$ as long as (i) the variance of these firms' exports to market 2 is not much larger than to market 1 and (ii) the variance of exports to a market is not decreasing too quickly with the exports to that market. The second part of (13) shows the effect of the total exports of firm $j$. If the amount sold on a market affects the volatility of growth rates on that market, the size of a firm's exports may affect the volatility of the growth rate of exports.

We now turn to a detailed analysis of (13) for different groups of exporters in our model. For simplicity, we will focus only on firms which always export and which sell at least in some periods to both markets, ${ }^{17}$ i.e. we consider firms for which $\underline{s} \lambda_{j i} \geq f$ for at least one market and $\bar{s} \lambda_{j i^{\prime}} \geq f$ on the other market. The first condition ensures that firm $j$ always exports to $i$ while the second guarantees that $j$ sometimes exports to $i^{\prime}$. Under these restrictions, there are two potential scenarios which we now turn to.

\subsubsection{Continuous exporters to both markets}

We first consider firms with $\lambda_{j i}>f / \underline{s}$ for $i=1,2$. These have a combination of high enough productivity and/or high enough demand on both markets, such that they always find it profitable to export to both

\footnotetext{
${ }^{17}$ Since our analysis concentrates on firms which always export, we do not consider firms which occasionally export to both markets, as they would not export in all years in our model. Firms which export permanently to one market and never sell to the other can easily be integrated and have a Herfindahl index of one.
} 
destinations. Firm j's growth rate on market $i$ is in this case:

$$
g_{j i}=\left\{\begin{aligned}
2 \frac{\bar{s}-\underline{s}}{\bar{s}+\underline{s}} & \text { with prob. 1/4 } \\
0 & \text { with prob. 1/2 } \\
-2 \frac{\bar{s}-\underline{s}}{\bar{s}+\underline{s}} & \text { with prob. } 1 / 4
\end{aligned}\right.
$$

and the variance of the growth rate of firm $j$ 's sales on market $i$ is consequently:

$$
V A R_{j i}=2\left(\frac{\bar{s}-\underline{s}}{\bar{s}+\underline{s}}\right)^{2} \equiv 2 \mu
$$

where $\mu$ is the squared coefficient of variation of $\zeta_{j i t}$. Since the firm exports continuously to both markets and the distribution of growth rates is independent of the market considered, the volatility of firm $j$ 's total exports is given by:

$$
V_{j}^{C}=2 \mu \operatorname{Herf}_{j}
$$

The above equation implies that sales diversification across markets is negatively associated with sales volatility, in line with the diversification effect of portfolio theory and shows that the Herfindahl index is a theory-consistent measure of export concentration.

\subsubsection{Firms occasionally exporting to one market}

We then consider exporters with a relatively high demand in a market and a relatively low demand in the other, i.e. exporters with $\lambda_{j i}>f / \underline{s}>\lambda_{j i}>f / \bar{s}$. Such firms always export to market $i$ but only export to market $i^{\prime}$ if they receive a high enough demand shock there. The distribution and the variance of growth rates on market $i$, where $j$ continuously exports, are given by equations (14) and (15), while on market $i^{\prime}$, they are:

$$
g_{j i^{\prime}}=\left\{\begin{array}{rc}
2 & \text { with prob. } 1 / 4 \\
0 & \text { with prob. } 1 / 2 \\
-2 & \text { with prob. } 1 / 4
\end{array}\right.
$$


where we set the growth rate equal to zero if there are two consecutive years of zero sales. ${ }^{18}$ The variance of the growth rate on market $i^{\prime}$ is therefore given by:

$$
V A R_{j i^{\prime}}=2 .
$$

The variance of exports to $i$ is larger if firm $j$ exports occasionally to $i$ than if it exports permanently to $i$. As evident from comparing (15) and (18) and from the definition of $\mu$, the variance differential between the two cases is stronger the larger the $\underline{s}$. If $\underline{s}$ is close to zero, a firm exporting permanently sells only very little when the demand shock is low, and is similar to an exporter selling only occasionally, which sells zero if demand is low. We can now express the volatility of exports of a firm selling continuously to $i$ and occasionally to $i^{\prime}\left(V_{j}^{O}\right)$ as a function of the Herfindahl index: ${ }^{19}$

$$
V_{j}^{O}=2 \mu \operatorname{Herf}_{j}+2(1-\mu) \omega_{j i^{\prime}}^{2}=(1+\mu) \operatorname{Herf}_{j}-(1-\mu) \sqrt{2 \operatorname{Herf}_{j}-1} .
$$

The first equality in (19) makes apparent that two forces determine $V_{j}^{O}$. The first $\left(2 \mu H e r f_{j}\right)$ is the standard diversification effect, captured by the Herfindahl index, which enters in an identical way to (16). The second $\left(2(1-\mu) \omega_{j i}^{2}\right)$ shows that the volatility of exports depends positively on the share of sales going to the market where the firm sells occasionally (composition effect). Since sales to $i^{\prime}$ are relatively volatile compared to their size, a larger fraction of sales to $i^{\prime}$ for a given Herfindahl index is associated with a higher volatility of exports. It is apparent from the comparison of (19) and (16) that, for a given Herfindahl index, $V_{j}^{C}<V_{j}^{O}$. The second equality in (19) shows that the volatility can be written solely as a function of the Herfindahl index, where $\sqrt{2 \operatorname{Herf}_{j}-1}>0$. Differentiating equation (19) with respect to $H \operatorname{Herf} f_{j}$ shows that $\mathrm{d} V_{j}^{O} / \mathrm{d} H \operatorname{erf} f_{j}<\mathrm{d} V_{j}^{C} / \mathrm{d} H \operatorname{erf} f_{j}$ (see Appendix) and that $\mathrm{d} V_{j}^{O} / \mathrm{d} H \operatorname{erf} f_{j}$ can be negative as long as $\operatorname{Herf}_{j}$ is not too large and $\underline{s}$ is not too small.

The intuition behind this result is as follows. First, if a firm has initially very concentrated sales, a one percentage point reallocation of market shares towards its smaller market ${ }^{20}$ reduces the Herfindahl index substantially, while this effect is much smaller for a firm with initially less concentrated sales. The diversification effect stemming from the reallocation of market shares is thus much smaller if the Herfindahl index is initially low. Second, the firm reallocates sales from a market where it exports

\footnotetext{
${ }^{18}$ In this case, the growth rate is strictly speaking undefined as it equals $0 / 0$, but the market has zero weight in these particular years. We show in the Appendix that this assumption is consistent with our approximation in (11).

${ }^{19}$ To derive the second equality, solve for $\omega_{j i^{\prime}}$ as a function of the Herfindahl index in (12) and plug in the first term of the first equality in (19). Rearranging gives the second equality.

${ }^{20}$ Market $i^{\prime}$ is "smaller" from firm j's perspective if $\chi_{j i}>\chi_{j i^{\prime}}$.
} 
continuously to a market where it exports occasionally (composition effect). The latter has a higher volatility and the variance differential between the two markets is increasing in $\underline{s}$. The composition effect is more likely to dominate the diversification effect if $\underline{\underline{s}}$ is large and the Herfindahl index is small.

The model developed in this section highlights a simple mechanism through which export diversification can increase the volatility of exports, namely by increasing the weight of markets to which a firm only exports occasionally. Since large exporters are likely to sell continuously to both markets, the $d i$ versification effect dominates when comparing the volatility of large exporters with different Herfindahl indices. Among small exporters, however, the weight of markets to which firms export occasionally is substantially larger, making it more likely that the composition effect dominates the diversification effect and that the relationship between the Herfindahl index and volatility turns negative. We provide a more formal discussion of this intuition in the Theory Appendix, and show using simulations that the mechanisms of the model extend to a setup with more than two countries.

\subsection{Discussion}

\subsubsection{Empirical relevance and alternative channels}

The model presented above is of course not the only possible mechanism generating a negative relationship between the Herfindahl index and the volatility of exports. In our setup, conditional on whether the firm exports continuously or occasionally, $\partial V A R_{j i} / \partial x_{j i}=0$ by assumption. If we however assumed that $V A R_{j i} \approx x_{j i}^{\rho}$, with $-1>\rho>-2$, we would also obtain a negative link between the Herfindahl index and the volatility of exports, even without fixed costs of exports (see equation (13)). A $\rho$ smaller than -1 means that the variance of exports to a destination decreases very quickly with each additional unit sold to that market. ${ }^{21}$ The rationale could be that firms learn quickly about consumers and market conditions with each additional unit sold in a destination, thereby reducing the uncertainty they face. If this rapid learning only happens for firms selling little on a market, we could replicate the pattern that the link between the Herfindahl and the volatility of exports is negative among small firms and positive among large firms. Justifying such a strong relationship between export size and the variance of shocks would however require strong assumptions and violate some empirical features that our approach matches. In particular, Table A1 in the Appendix tests that two main features of our model hold empirically across all firm-destination pairs in our sample: (i) when controlling for $x_{j i}, V A R_{j i}$ is decreasing in the number of

\footnotetext{
${ }^{21}$ In terms of our notation, this would mean that $\bar{s}$ and $\underline{s}$ are a function of $\chi_{j i}$ such that $\partial\left(\bar{s}_{j i}-\underline{s}_{j i}\right)^{2} / \partial \chi_{j i}<<0$. Note that our fixed costs of export are akin to introducing a very negative $\rho$ around the point where a firm switches from being an occasional to a permanent exporter on a market.
} 
years that the firm-destination pair is active (the empirical counterpart to the distinction between permanent and occasional exports in the model ${ }^{22}$ ), and (ii) controlling for the number of years in which a firm sells to a given destination, regressing $\ln \left(V A R_{j i}\right)$ on $\ln \left(x_{i j}\right)$ gives a coefficient close to zero (although significantly different from it) and most importantly much larger than -1. Furthermore, we emphasize the role of fixed costs of exports in the model since there is substantial evidence that these do play an important role on export markets. The fixed costs $f$ are costs that firms have to incur per year and per country to which they actually ship and are in line with a growing literature pointing to the existence of substantial fixed costs of shipment to a market (see Alessandria et al., 2010; Hornok and Koren, 2015; Kropf and Sauré, 2014). ${ }^{23}$

Finally, our explanation for the differential impact of the Herfindahl index on volatility among small and large exporters relies on the idea that the composition effect is stronger among small exporters. In other words, our theoretical explanation requires that (i) occasional exports to some destinations are more prevalent among small exporters and that (ii) a marginal increase in the Herfindahl index raises the prevalence of occasional exports more among small than among large exporters. ${ }^{24}$ We look at these two assumptions in turn. First, the left panel of Figure 2 plots the relationship between the size of a firm's exports and the share of destinations to which it sells for 1 to 7 years, where we think of the number of years as an empirical counterpart to the continuity of export flows in the model. As expected, larger exporters tend to sell longer to each of their destinations, i.e. occasional exports are less prevalent among large exporters. The right panel of Figure 2 takes a different measure of continuity and plots the probability that a firm exports to a given destination given that it exported to that destination in the previous year. ${ }^{25}$ This measure is also clearly increasing with a firm's initial exports. Second, we regress the average number of years in which a firm has positive exports to a market ${ }^{26}$ on the Herfindahl index and an interaction of the Herfindahl with a dummy for each quintile of firms' export size. The results are reported in Table 2. The linear regressions (OLS) show that the Herfindahl index has a stronger marginal impact on the prevalence of occasional exports for small than for large exporters, and this result is robust to using Poisson pseudo-maximum-likelihood (PPML) estimation which deals with the problem that our

\footnotetext{
${ }^{22}$ As in (17), to compute the variance of exports, we set the growth equal to zero when it would otherwise be missing. The negative coefficient on the number of years would become much more negative if we did treat these growth rates as missing and excluded them from the computation of the destination-specific volatility. None of the other coefficients would be affected.

${ }^{23}$ Other theoretical contributions, such as Irarrazabal and Opromolla (2009) or Impullitti et al. (2013), also include perperiod fixed costs of export.

${ }^{24}$ This can be seen formally from (40) in the Theory Appendix.

${ }^{25}$ We thank an anonymous referee for this suggestion.

${ }^{26}$ We compute the number of years in which firm $j$ exports to $i\left(n_{j i}\right)$ and use the weighted average: $\sum_{i} \frac{x_{j i 0}}{x_{j 0}} n_{j i}$ as the dependent variable.
} 

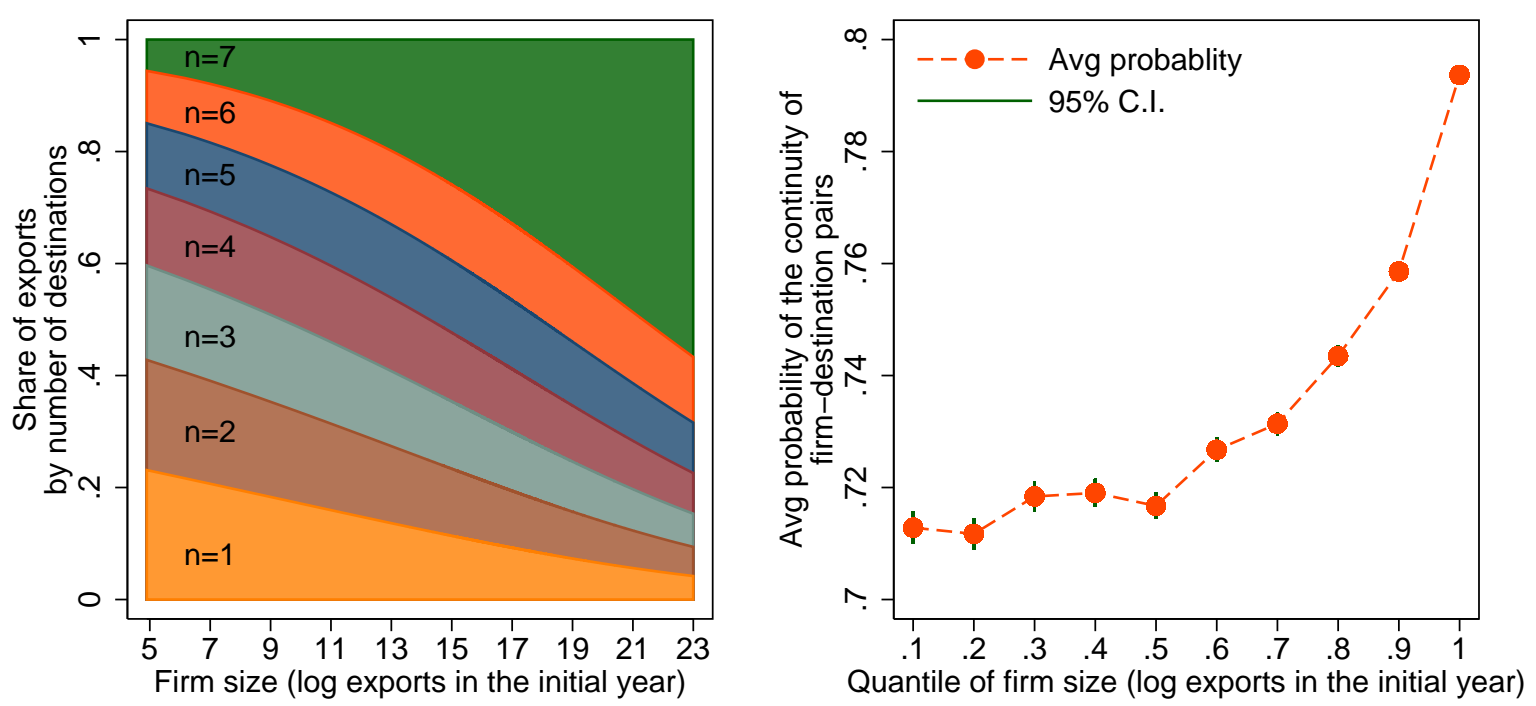

Figure 2. Firm size and export continuity. The sub-figure on the left shows, for exporters of different sizes, the shares of destinations to which the firm exports from only once $(n=1)$ up to seven times $(n=7)$. The sub-figure on the right shows, for exporters of different sizes, the average probability that a firm-destination pair active at $t-1$ is still active at $t$ in the data. Source: CCTS.

dependent variable is bounded.

\subsubsection{Alternative interpretation: experimenting new destinations}

The analysis in Sections 3.2 and 3.3 takes a steady state perspective in the sense that firms have in each period the same probability of exporting to a given market. The period 2000-2006 is however a time of large export growth for China, in which many Chinese firms experimented new destination markets. ${ }^{27}$ To understand the impact of these particular circumstances, we provide a simple extension of the theoretical setup. Assume that a firm does not know its demand parameter $\chi_{j i}$ on market $i$ if it has never exported there (this assumption is similar to Albornoz et al. (2012)). In the first year that it does, the firm needs to pay the fixed costs $f$ before it observes $\chi_{j i}$ and the realization of $\zeta_{j i t}$. This means that the firm sells a positive amount on $i$ (we assume $\chi_{j i}>0$ ) if it decides to sell there for the first time. If firm $j$ observes a high enough $\chi_{j i}$ on $i$ (such that $f<\bar{s} \lambda_{j i}$ ), it subsequently behaves as an occasional or permanent exporter to that market as described in Section 3.3.2. ${ }^{28}$ If firm $j$ observes a low $\chi_{j i}\left(f>\bar{s} \lambda_{j i}\right)$, on the other hand, it exports $\sigma \zeta_{j i t} \lambda_{j i}$ in the first year and never exports again. If the measure of market share $\omega_{j i}$ is affected by such experimenting behavior, we show in the Theory Appendix that this case is

\footnotetext{
${ }^{27}$ For example, on the balanced sample of continuous exporters present in our CCTS sample, the median number of destinations to which a firm exports grew from 3 in 2000 to 5 in 2006.

${ }^{28}$ Strictly speaking, the exports in the first year may differ from the analysis in Section 3 if the firm draws the short run shock $\underline{s}$ and has $\chi_{j i}$ and $\varphi$ such that $\underline{s} \lambda_{j i}<f<\bar{s} \lambda_{j i}$. In all subsequent years, however, the firm behaves as previously described.
} 
Table 2. Firm size and the composition effect

Dependent variable: weighted average number of years of exporting. Samples: CCTS and matched CCTS-ASIF.

\begin{tabular}{|c|c|c|c|c|c|c|}
\hline & \multicolumn{3}{|c|}{ CCTS } & \multicolumn{3}{|c|}{ Matched CCTS-ASIF } \\
\hline & $\begin{array}{l}\text { OLS } \\
(1)\end{array}$ & $\begin{array}{l}\text { OLS } \\
(2)\end{array}$ & $\begin{array}{l}\text { Poisson } \\
\text { (3) }\end{array}$ & $\begin{array}{l}\text { OLS } \\
(4)\end{array}$ & $\begin{array}{l}\text { OLS } \\
(5)\end{array}$ & $\begin{array}{l}\text { Poisson } \\
\text { (6) }\end{array}$ \\
\hline $1(\operatorname{size} \leq 20 \%)$ & $\begin{array}{l}4.650 * * * \\
(0.044)\end{array}$ & $\begin{array}{l}4.654 * * * \\
(0.043)\end{array}$ & $\begin{array}{l}1.552 * * * \\
(0.010)\end{array}$ & $\begin{array}{l}4.995 * * * \\
(0.060)\end{array}$ & $\begin{array}{l}4.993^{* * * *} \\
(0.070)\end{array}$ & $\begin{array}{l}1.613^{* * * *} \\
(0.014)\end{array}$ \\
\hline $1($ size $>20 \%$ \& size $\leq 40 \%)$ & $\begin{array}{l}0.527 * * * \\
(0.058)\end{array}$ & $\begin{array}{l}0.672 * * * \\
(0.056)\end{array}$ & $\begin{array}{l}0.098^{* * * *} \\
(0.012)\end{array}$ & $\begin{array}{l}0.554 * * * \\
(0.080)\end{array}$ & $\begin{array}{l}0.648^{* * * *} \\
(0.090)\end{array}$ & $\begin{array}{l}0.103 * * * \\
(0.017)\end{array}$ \\
\hline $1($ size $>40 \% \&$ size $\leq 60 \%)$ & $\begin{array}{l}0.903 * * * \\
(0.056)\end{array}$ & $\begin{array}{l}1.083 * * * \\
(0.054)\end{array}$ & $\begin{array}{l}0.165^{* * * *} \\
(0.011)\end{array}$ & $\begin{array}{l}1.018 * * * \\
(0.079)\end{array}$ & $\begin{array}{l}1.071^{* * * *} \\
(0.090)\end{array}$ & $\begin{array}{l}0.182 * * * \\
(0.016)\end{array}$ \\
\hline $1($ size $>60 \% \&$ size $\leq 80 \%)$ & $\begin{array}{l}1.262 * * * \\
(0.054)\end{array}$ & $\begin{array}{l}1.511 * * * \\
(0.053)\end{array}$ & $\begin{array}{l}0.226^{* * * *} \\
(0.011)\end{array}$ & $\begin{array}{l}1.099 * * * \\
(0.078)\end{array}$ & $\begin{array}{l}1.286^{* * * *} \\
(0.089)\end{array}$ & $\begin{array}{l}0.195 * * * \\
(0.016)\end{array}$ \\
\hline $1($ size $>80 \% \&$ size $\leq 100 \%)$ & $\begin{array}{l}1.675 * * * \\
(0.052)\end{array}$ & $\begin{array}{l}1.975 * * * \\
(0.052)\end{array}$ & $\begin{array}{l}0.292^{* * * *} \\
(0.010)\end{array}$ & $\begin{array}{l}1.477 * * * \\
(0.076)\end{array}$ & $\begin{array}{l}1.621^{* * * *} \\
(0.087)\end{array}$ & $\begin{array}{l}0.255^{* * * *} \\
(0.015)\end{array}$ \\
\hline Herfindahl & $\begin{array}{l}1.506^{* * * *} \\
(0.053)\end{array}$ & $\begin{array}{l}1.397 * * * \\
(0.051)\end{array}$ & $\begin{array}{l}0.266^{* * * *} \\
(0.012)\end{array}$ & $\begin{array}{l}0.817 * * * \\
(0.077)\end{array}$ & $\begin{array}{l}0.855^{* * * *} \\
(0.089)\end{array}$ & $\begin{array}{l}0.148^{* * * *} \\
(0.019)\end{array}$ \\
\hline Herfindahl $\times 1($ size $>20 \%$ \& size $\leq 40 \%)$ & $\begin{array}{l}-0.401 * * * \\
(0.071)\end{array}$ & $\begin{array}{l}-0.539 * * * \\
(0.068)\end{array}$ & $\begin{array}{l}-0.078^{* * *} * \\
(0.015)\end{array}$ & $\begin{array}{l}-0.054 \\
(0.105)\end{array}$ & $\begin{array}{l}-0.217^{*} \\
(0.116)\end{array}$ & $\begin{array}{l}-0.021 \\
(0.023)\end{array}$ \\
\hline Herfindahl $\times 1($ size $>40 \%$ \& size $\leq 60 \%)$ & $\begin{array}{l}-0.690 * * * \\
(0.069)\end{array}$ & $\begin{array}{l}-0.856^{* * *} \\
(0.067)\end{array}$ & $\begin{array}{l}-0.131 \text { *** } \\
(0.014)\end{array}$ & $\begin{array}{l}-0.399 * * * \\
(0.105)\end{array}$ & $\begin{array}{l}-0.572 * * * \\
(0.116)\end{array}$ & $\begin{array}{l}-0.081 * * * \\
(0.022)\end{array}$ \\
\hline Herfindahl $\times 1($ size $>60 \%$ \& size $\leq 80 \%)$ & $\begin{array}{l}-0.955 * * * \\
(0.068)\end{array}$ & $\begin{array}{l}-1.197 * * * \\
(0.066)\end{array}$ & $\begin{array}{l}-0.178^{* * *} * \\
(0.013)\end{array}$ & $\begin{array}{l}-0.326^{* * * *} \\
(0.104)\end{array}$ & $\begin{array}{l}-0.641^{* * *} * \\
(0.115)\end{array}$ & $\begin{array}{l}-0.071 * * * \\
(0.021)\end{array}$ \\
\hline Herfindahl $\times 1($ size $>80 \% \&$ size $\leq 100 \%)$ & $\begin{array}{l}-1.321 * * * \\
(0.068)\end{array}$ & $\begin{array}{l}-1.566^{* * * *} \\
(0.066)\end{array}$ & $\begin{array}{l}-0.237 * * * \\
(0.013)\end{array}$ & $\begin{array}{l}-0.675^{* * *} \\
(0.104)\end{array}$ & $\begin{array}{l}-0.955^{* * *} * \\
(0.114)\end{array}$ & $\begin{array}{l}-0.126 * * * \\
(0.020)\end{array}$ \\
\hline Prov-ind-own dummies & No & Yes & Yes & No & Yes & Yes \\
\hline $\begin{array}{l}\text { \# Observations } \\
\text { R-squared }\end{array}$ & $\begin{array}{l}23,822 \\
0.111\end{array}$ & $\begin{array}{l}23,822 \\
0.338\end{array}$ & $\begin{array}{l}23,822 \\
0.111\end{array}$ & $\begin{array}{l}8,387 \\
0.154\end{array}$ & $\begin{array}{l}8,387 \\
0.598\end{array}$ & $\begin{array}{l}8,387 \\
0.154\end{array}$ \\
\hline
\end{tabular}

Note. This table reports results of the differential marginal impact of diversification on the prevalence of occasional exports for firms of different sizes. Columns 1-3 contain results from the CCTS sample, and Columns 4-6 from the matched CCTS-ASIF sample. The dependent variable is the weighted average number of years of exporting, with the weight being the country's share in the firm's total export sales. The explanatory variables are dummies for firm size quintiles, Herfindahl index, and their interactions. Industry classification is based on the HS2 categories which have the highest shares in firm's exports for the CCTS sample, and is based on 4-digit Chinese GB/T sector codes for the matched CCTS-ASIF sample. Prov-ind-own dummies are dummies for each province-industry-year combination. All other variables are defined as in Table 1. Robust standard errors are in parentheses, and superscripts *, **, *** indicate significance at $10 \%, 5 \%$, and $1 \%$ levels respectively. 
in many respects similar to the one developed in Section 3.3. Firms with a higher Herfindahl index can in this case also have a lower volatility because they export only in some years to some destinations.

Although they generate similar predictions, the interpretation of the present extension fundamentally differs from the model developed in Section 3.2. In Section 3.2, a firm is active in a given set of countries $^{29}$ and, given this set, reacts to short-run shocks by adapting its sales to these countries. In particular, if there were no short-run shocks, the volatility of exports would be equal to zero. In the present section, however, the link between the Herfindahl index and the volatility of exports comes from a temporary change in the set of markets to which the firm sells. In other words, the volatility of exports would be positive even if there were no short-run shocks, and the relationship between the Herfindahl and the volatility of exports has little to do with what we understand as diversification. We follow two strategies to ensure that our empirical results are not a result of market experimenting. First, we use as a baseline measure of $\omega_{j i}$ the share of market $i$ in firm j's exports in the first year: $x_{j i 0} / x_{j 0}$. This is not affected by the later market experimentation of firms and ensures that the correlation we observe is not due to that motive. Second, we show in Section 4 that the results we observe are not driven by those exports flow resembling a failed experimentation.

\section{Econometric Evidence}

In this section, we provide an econometric test of the relationship between the volatility and diversification of export sales across markets inspired by the pattern highlighted in Figure 1. More specifically, we show that these patterns hold for a wide array of controls, specifications and definitions in different samples. Furthermore, we provide some evidence on the importance of destinations to which firms occasionally export for the relationship between diversification and volatility, as suggested by the theory, and examine other potential channels which could generate the observed relationship. Finally, we discuss the issue of endogeneity and attempt to address it using an instrumental approach.

\footnotetext{
${ }^{29}$ A firm is "active" on a market if its long-run parameters are such that it sells a positive amount for some values of the short run demand shocks.
} 


\subsection{Baseline specification}

The baseline specification of our empirical analysis is:

$$
\operatorname{Vol}_{j}=\beta_{0}+\beta_{1} \operatorname{Herf}_{j}+\beta_{2} \operatorname{Size}_{j}+\beta_{3} \operatorname{Herf}_{j} \times \operatorname{Size}_{j}+\gamma \Theta_{j}+d_{r}+d_{s}+d_{o}+\varepsilon_{i}
$$

where $\operatorname{Vol}_{j}$ is the volatility of firm $j$ 's export sales (as defined in (1)), $\operatorname{Herf}_{j}$ is the Herfindahl index of the firm's export market destinations (see (2)) and $\mathrm{Size}_{j}$ is the log of firm $j$ 's worldwide exports. We also include province $\left(d_{r}\right)$, industry $\left(d_{s}\right)$, and ownership $\left(d_{o}\right)$ dummies to control for any omitted region, industry, and ownership-specific effects. $\Theta_{j}$ is a vector of firm-level characteristics which may affect the volatility of firms' exports and be correlated with some of our variables of interest. First, we control for the average income and the average volatility of GDP growth of the destinations to which firm $j$ exports. ${ }^{30}$ Firms exporting to richer or less volatile countries may have less volatile exports and could differ systematically in terms of size or diversification. Similarly, we control for the volatility of the product basket that the firm exports, which is a weighted average of the volatility of products exported by a firm, where the weights are the share of each product in the firm's export sales. Second, we control for the absolute value of the average export growth over the period, as firms growing or shrinking fast on the export market may appear mechanically more volatile. Third, to ensure that our results are not driven by firm-specific trends in the number of destinations or products exported, we control for the change of the number of destinations and of products between 2000 and 2006. Finally, when using the matched sample, we control for a wide range of firm-level balance-sheet items such as the total (including domestic) sales of the firm, firm age, wage, capital intensity, and leverage ratio. It is worth emphasizing that we run equation (20) on a cross-section of exporters, and that the Herfindahl index is defined at the beginning of the period, namely year 2000, and so are the firm-level balance sheet controls (exports, sales, etc.).

The results of the baseline estimations are reported in Table 3. Columns 1-4 present the results using the customs sample without balance sheet controls while Columns 5-8 are based on the matched sample and include a full set of firm-level balance-sheet controls. Interestingly, the main coefficients of interest $\left(\beta_{1}\right.$, $\left.\beta_{2}, \beta_{3}\right)$ confirm the pattern observed in Figure 1. The coefficient on the Herfindahl index $\left(\beta_{1}\right)$ is negative and significant, showing that for small exporters (firms with low exports), more diversification of export destinations is associated with a higher volatility of exports. This result, which goes against standard

\footnotetext{
${ }^{30}$ Details on the construction of these variables are available in the Data Appendix.
} 
portfolio theory, is in line with the downward slope of the upper curve in Figure 1. The coefficient $\beta_{2}$ on size is negative, reflecting that firms exporting more have on average more stable exports. The negative relationship between the volume and the volatility of exports at the firm level is in line with the literature, as discussed in Section 2.3. The positive coefficient $\beta_{3}$, on the interaction between the Herfindahl index and the size of exports, shows that the marginal effect of the Herfindahl index on the export volatility is increasing with export sales. Figure 3 plots the marginal effect of the Herfindahl index of export destinations on volatility as estimated in Columns 3 and 7 of Table 3 and illustrates that, in our sample, a lower Herfindahl index (more diversified exports) is associated with a higher export volatility for small exporters and with a lower volatility for large exporters.

Columns 4 and 8 also include the results on the product dimension of diversification. Interestingly, the patterns are similar to the ones observed for diversification across destinations: the coefficient on the product Herfindahl is negative, while the coefficient on the interaction between the product Herfindahl and size is positive and significant. It is indeed conceivable that a similar mechanism to the one we propose is at play on the product dimension if there are fixed costs of exports per product (e.g. providing quality tests each year that a product is exported, updating packaging information, etc.). To simplify exposition, we will only report the results on the destination dimension of exports in the paper, leaving a number of robustness checks on the product dimension to the Appendix in Table A4. The same patterns broadly hold for product diversification as for destination diversification, the results being slightly less robust for the former. Finally, we have also redefined the Herfindahl index at the product-destination pair level and obtained qualitatively the same results, see Table A2 in the Appendix.

The estimated coefficients on the other controls are as expected from the literature: more experienced (older), more skill-intensive (higher-wage), and better financed (lower leverage ratio) firms have less volatile exports. Controlling for log exports $\left(\right.$ Size $\left._{i}\right)$, firms with higher total sales (exports plus domestic sales) have a higher volatility of exports, in line with Vannoorenberghe (2012). Firms exporting to highincome countries have lower export volatility (in line with Kurz and Senses (2016)), and exporting to more volatile markets tends to make firms' exports more volatile. As expected, the absolute value of the average growth of exports is positively correlated with export volatility, reflecting the fact that firms growing or shrinking fast appear mechanically more volatile. The change in the number of destinations between the first and the final year is negatively associated with a firm's export volatility. The coefficients of interest however are virtually unaffected by the inclusion of these additional controls. 


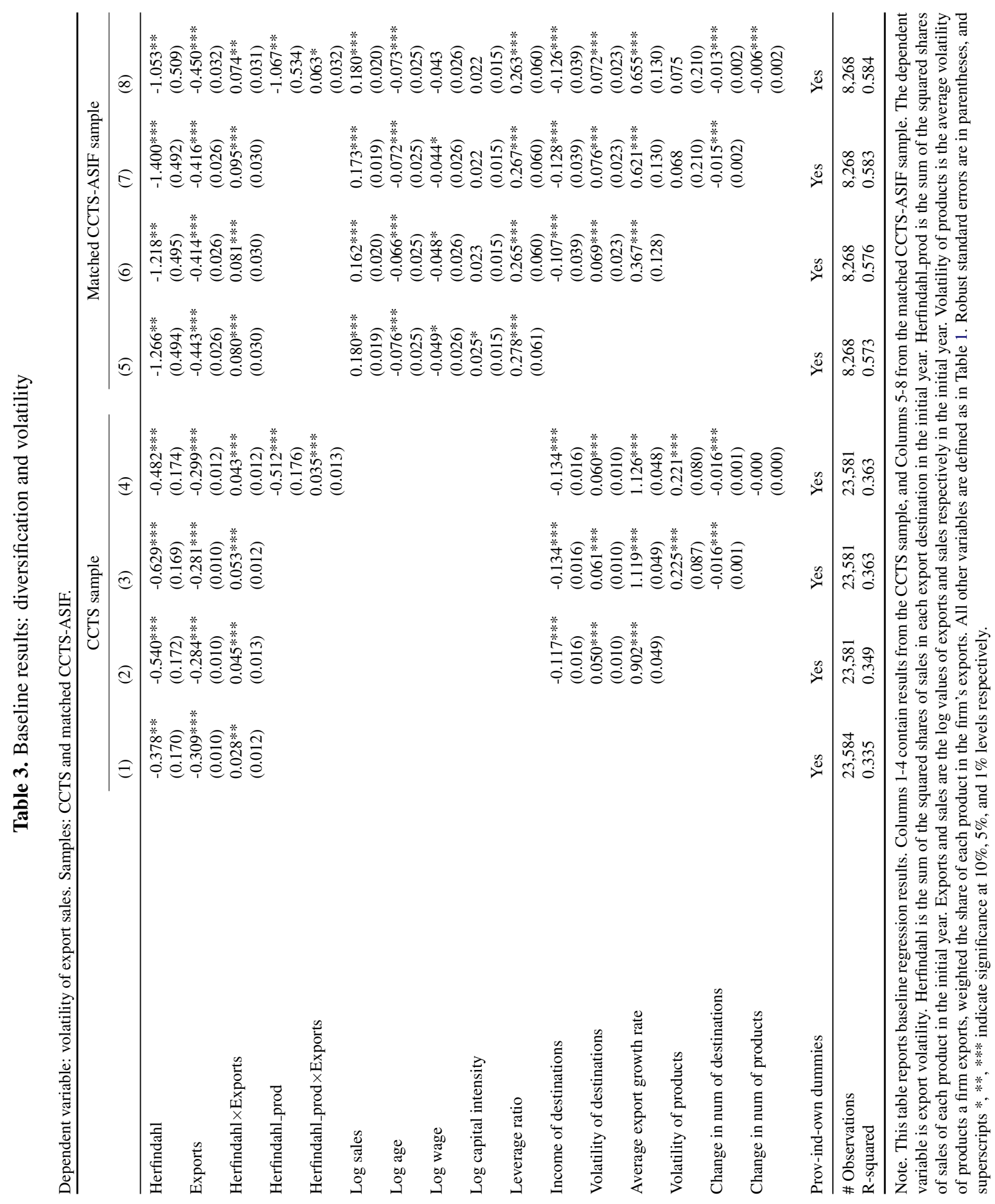




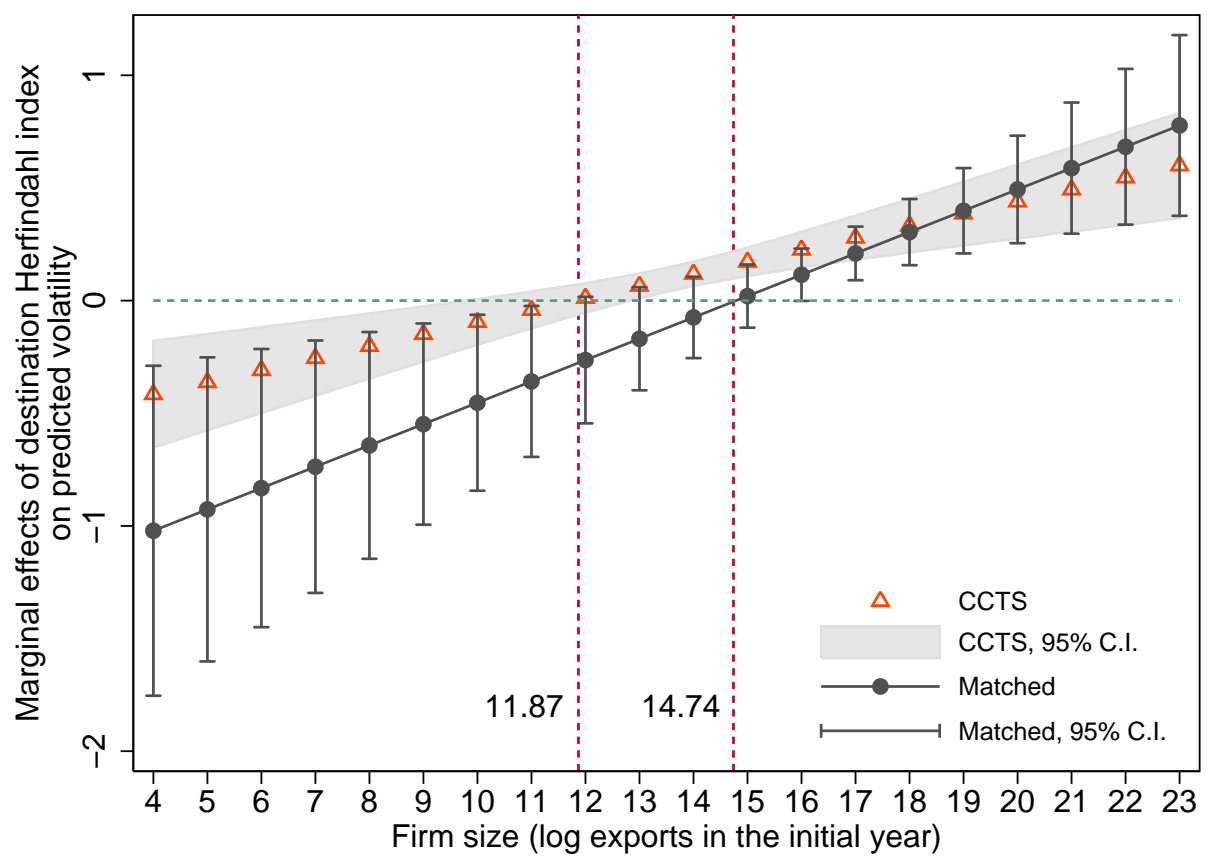

Figure 3. Marginal effects of diversification on predicted volatility for firms of different sizes. This figure plots the predicted marginal effects as well as their $95 \%$ confidence intervals from the estimated results in Columns 3 and 7 of Table 3. Source: CCTS and matched CCTS-ASIF.

Correlation between size and Herfindahl. One concern with the above regression is that our measures of diversification and firm size may be correlated, since large firms are more likely to have a diversified sales profile. This is confirmed in a simple correlation analysis which shows that the Herfindahl index and the log export sales indeed are negatively correlated at the $1 \%$ significance level in both the customs and the matched samples. Note, however, that the correlation is only imperfect, with the correlation coefficient being -0.18 and -0.07 in the the customs and the matched samples, respectively. As can be seen in Table 4, the Herfindahl index is not too unevenly distributed for each firm size category. Particularly, there is a nontrivial proportion of large firms which exhibit high Herfindahl index (highly concentrated), and a fraction of small firms with low Herfindahl index (highly diversified).

\subsection{Occasional exports to some destinations}

Our model suggests that the observed volatility-diversification relationship obtains because some firms do not export continuously to some markets. As shown in Figure 4, there is a very large prevalence of non-continuous export flows at the firm-level and Figure 2 shows that the length of export spells is related to the size of the firm. We now explore whether such flows drive the results of Table 3 through two types of tests. 
Table 4. Firm size and diversification

Sample: CCTS

\begin{tabular}{llrrrr}
\hline & & \multicolumn{4}{c}{ Herfindahl index } \\
\cline { 3 - 6 } & & Low & Medium & High & Total \\
\hline Firm Size & Small & $7 \%$ & $9 \%$ & $15 \%$ & $30 \%$ \\
& Medium & $10 \%$ & $11 \%$ & $11 \%$ & $32 \%$ \\
& Large & $13 \%$ & $12 \%$ & $12 \%$ & $37 \%$ \\
& Total & $30 \%$ & $32 \%$ & $37 \%$ & $100 \%$ \\
\hline
\end{tabular}

Note. This table reports the distribution of firms in different clusters. Numbers denote percentage of observations in both the CCTS and the matched CCTS-ASIF samples. Firm size groups are defined according to the tertiles of the distribution of firm size within each province-industry-ownership cell.

First, we decompose the volatility of exports between the contribution of an intensive and and extensive margin, where we define the extensive margin as the share of firm $j$ 's export growth at $t$ coming from the change in the set of destinations to which it exports between $t-1$ and $t .^{31}$ We look at the relative contribution of the extensive margin for firms of different sizes and of different degrees of diversification. To decompose the volatility, we first construct the growth rate of exports coming from changes in exports to the destinations where the firm already exported in the previous year $\left(g_{j t}^{I N T}\right)$ :

$$
g_{j t}^{I N T}=2 \sum_{i} \frac{\left(x_{j i t}-x_{j i t-1}\right) \times \mathbb{1}\left(x_{j i t}>0, x_{j i t-1}>0\right)}{x_{j t}+x_{j t-1}},
$$

where $\mathbb{1}$ is the indicator function which takes the value of 1 if both conditions in bracket are fulfilled and the value of 0 otherwise. The growth of the firm coming from a change in the set of markets is $g_{j t}^{E X T}=g_{j t}-g_{j t}^{I N T}$. We calculate the contribution of yearly changes in the set of destinations ("the extensive margin") to the variance of a firm's exports following Kramarz et al. (2015) ${ }^{32}$. Figure 5 shows the average value of this contribution for different levels of export size and of the Herfindahl index of exports. Two patterns emerge clearly: (i) the extensive margin is a much stronger contributor to the firm's volatility of exports among small exporters than among large exporters, and (ii) the relative importance of the extensive margin is decreasing with the concentration of a firm's exports across destinations. This is precisely what our theory suggests: smaller exporters with a more diversified export portfolio of destinations are more volatile as the role of the occasional exporting is stronger for them.

Second, we replicate our baseline analysis disregarding the exports to any destination to which a firm does not continuously export. For example, if a firm exports in all years to the U.K. and France, but

\footnotetext{
${ }^{31}$ We thank an anonymous referee for suggesting this approach.

${ }^{32}$ We compute this quantity as $\left[\operatorname{VAR}\left(g_{j t}^{E X T}\right)+2 \frac{\operatorname{VAR}\left(g_{j t}^{E X T}\right)}{\operatorname{VAR}\left(g_{j t}^{E X T}\right)+\operatorname{VAR}\left(g_{j t}^{I N T}\right)} \operatorname{COV}\left(g_{j t}^{E X T}, g_{j t}^{I N T}\right)\right] / V_{j}$.
} 


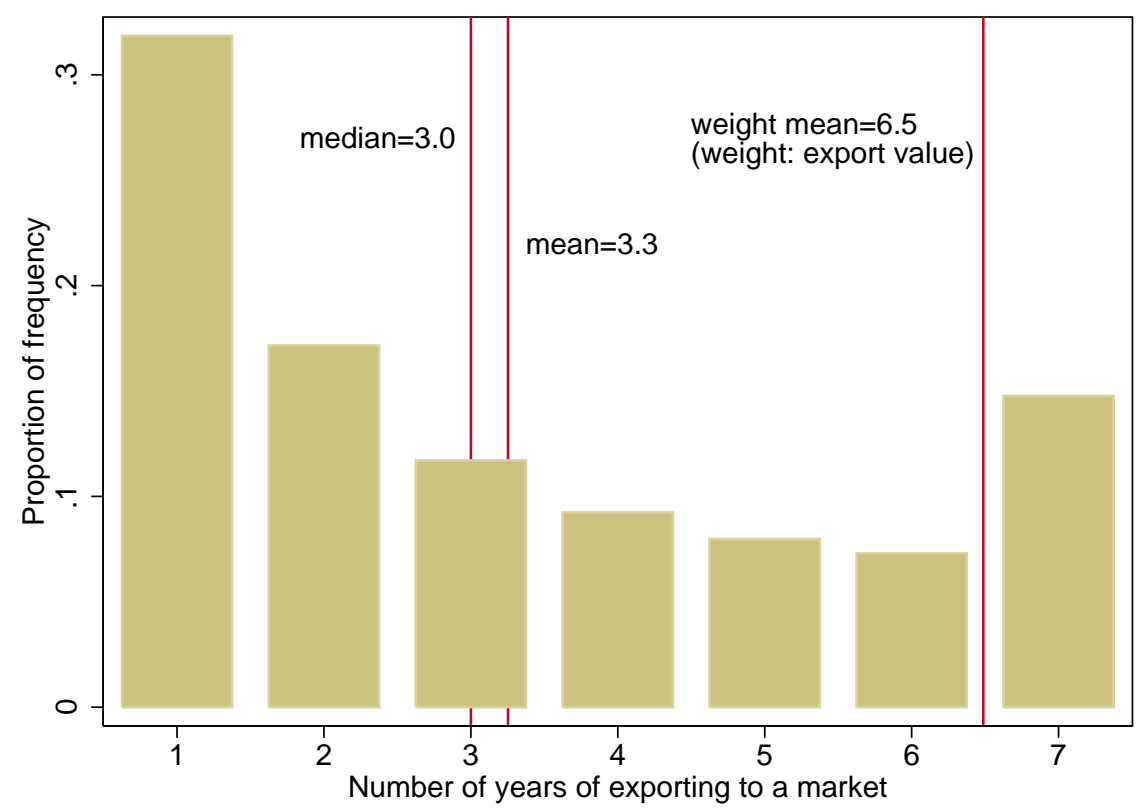

Figure 4. Distribution of number of years for which a firm exports to a destination. This figure shows the distribution of the number of years for which a firm-destination export value is positive. The y-axis is the proportion of the frequency. Source: CCTS.

only during five years to Germany, we re-compute the "worldwide" exports of that firm as the export sales to the U.K. and France in the beginning of the period as well as a Herfindahl index and a volatility measure based solely on the firm's sales to France and the U.K. in 2000. The results of this exercise are reported in Column 2 of Table 5, where the Herfindahl index has a positive but insignificant effect on volatility. The interaction between the Herfindahl index and size is now close to zero and insignificant. In other words, conditioning on markets to which it continuously exports, a small exporter does not have a different relationship between the Herfindahl index and volatility than a large exporter. This exercise confirms the role of markets to which firms export occasionally in explaining the diversification-volatility relationship and is in line with our theory. ${ }^{33}$ Columns 3-4 of Table 5 conduct a similar exercise but keeping all markets to which a firm exports at least 6 years or at least 2 years. As expected, the results are between the extreme cases of Columns 1 and 2, and confirm that our main results are not driven solely by destinations to which firms export only one year. Similarly, Column 5 shows that our results hold even excluding destinations to which firms export all years. The opposition between occasional and continuous destinations is thus not strict: different lengths of spells among occasional destinations appear sufficient to generate our results.

\footnotetext{
${ }^{33}$ In terms of the theory, this exercise is akin to isolating the link between the Herfindahl index and volatility conditional on the status of continuous exporter.
} 


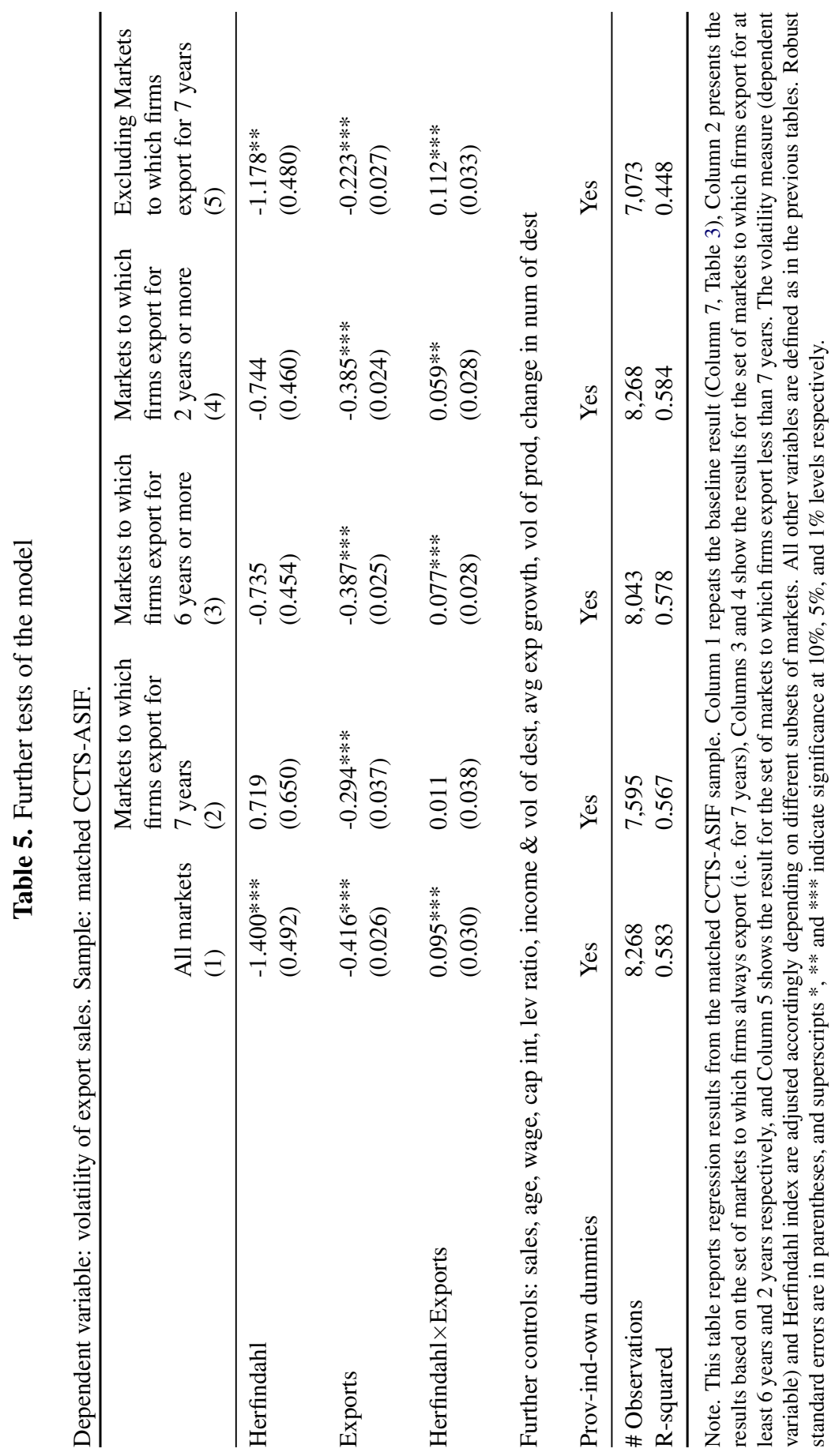



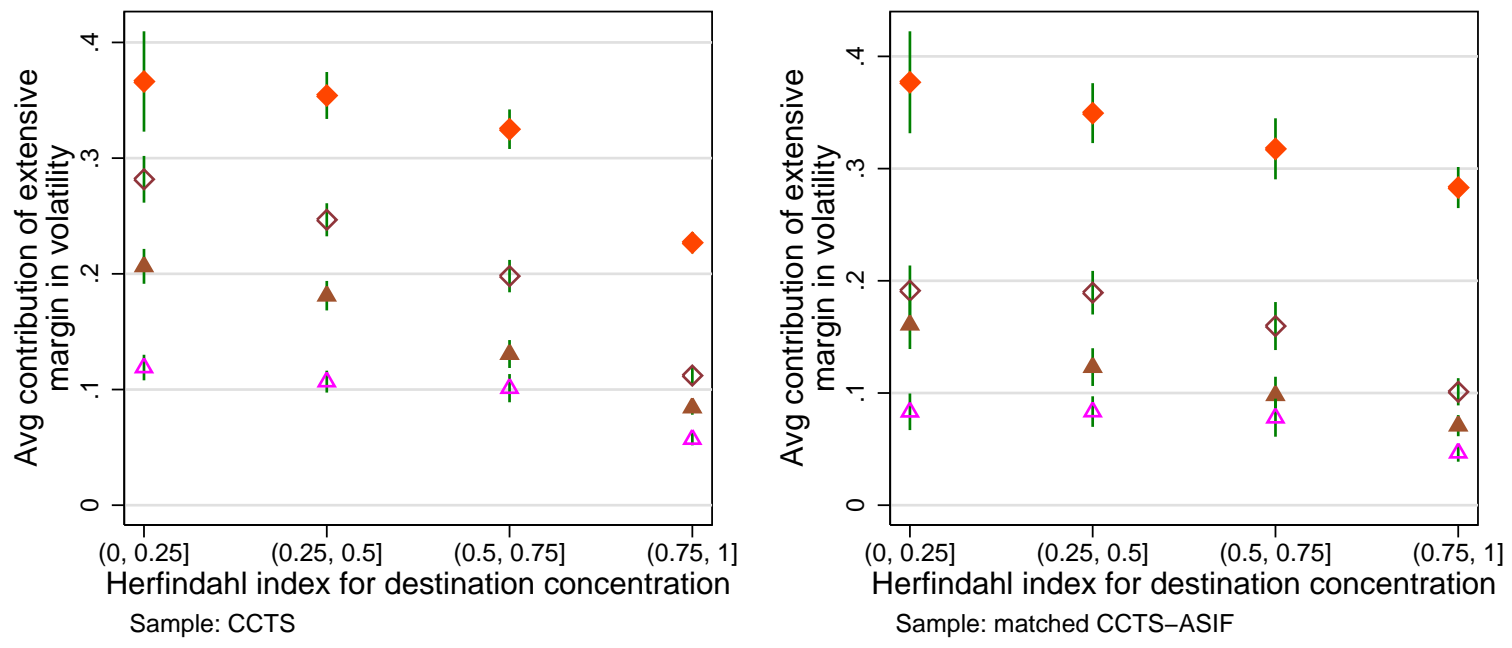

Size: 1 st quartile $\diamond$ Size: 2 nd quartile $\quad \Delta$ Size: 3rd quartile $\quad \Delta$ Size: 4th quartile $\quad-95 \%$ C.I.

Figure 5. Contribution of extensive margin in firm export volatility. This figure shows the average contribution of the extensive margin (at market dimension) in firms' export volatility, following a similar decomposition approach to Kramarz et al. (2015). Export volatility is measured as log of squared deviation in export growth rate from firm's own average. Source: CCTS and Matched CCTS-ASIF.

\subsection{Robustness and discussion}

The present section explores a number of robustness checks using different definitions of variables and samples of firms. For the sake of space, we only report results for the matched sample, but all the conclusions that do not require balance sheet data also hold in the CCTS sample.

\subsubsection{Alternative measures of the main variables}

Next we check whether our results are sensitive to alternative measures of volatility, firm size and of export concentration. Column 1 of Table 6 uses an alternative measure of volatility based on a firmspecific detrending of the growth rate of exports. To compute this alternative measure, we conduct a firm-specific regression of the growth rate of exports on a constant, a linear time trend and a squared time trend, and take the squared residuals as our measure of volatility. The results are hardly affected. Columns 2 to 4 show that, using a firm's total employment, assets or TFP as measures of firm size, the coefficient on the interaction between the Herfindahl index and the measure of size are again positive, although insignificant in the case of employment. This generally confirms our baseline results that larger firms are more likely to benefit from a diversification effect. ${ }^{34}$ We also experiment with different

\footnotetext{
${ }^{34}$ It is worth noting that the coefficient on the Herfindahl index becomes insignificant or positive using these alternative measures of size. We are thus not claiming that export diversification raises the volatility of exports among small exporters for
} 
measures of export concentration, such as the share of exports going to the main export destination in 2000 (Column 5) or the number of export destinations to which the firm sells in 2000 (Column 6). Both results are consistent with our baseline result. Note that because the number of destinations is a measure of diversification while the other measures we use are measures of concentration, it is unsurprising that the signs of the main coefficients of interest are reversed in Column 6.

We also construct a measure of diversification taking into account the covariance of GDP growth between export markets and the fact that some destinations have a more volatile GDP growth than others. As we highlight in the Theory Appendix, relaxing the assumption of zero covariance between markets in equation (11) gives:

$$
V_{j}=\sum_{i, m} \omega_{j i 0} \omega_{j m 0} C O V_{j i m}
$$

where $C O V_{j i m}$ is the covariance between export growth on markets $i$ and $m$ from the perspective of firm $j$, and where $C O V_{j i i}=V A R_{j i}$. We proxy for the right-hand side of (22) using the variance-covariance matrix of GDP growth across all destinations and use this proxy as a modified version of our baseline Herfindahl index. ${ }^{35}$ The results, reported in Column 7 of Table 6 again generate similar results. Interestingly, the firm size threshold (in logs) below which the diversification-volatility relationship turns positive is similar across different measures of diversification. Finally, Column 8 constructs the Herfindahl index based on the average sales to a destination over the whole period, i.e. in Column 8, we define $\operatorname{Herf}_{j} \equiv$ $\sum_{i, t}\left(x_{j i t} / \sum_{t} x_{j t}\right)^{2}$. The results are virtually unchanged. Our results thus appear very robust to using different measures of diversification than our baseline Herfindahl index.

\subsubsection{Market experimentation}

As emphasized in Section 3.4.2, a firm that sells occasionally (i.e. not every year) to a market may do so because it tries its luck in a destination before permanently exiting it upon seeing that the demand for its product is too low. As described in the Theory Appendix, constructing the Herfindahl index based on the export patterns of the first year makes it unlikely that such a behavior can mechanically drive our results. In the following, we present additional evidence that this experimenting behavior - which has little to do with diversification — does not drive our result.

For this, we construct the size, Herfindahl and volatility of exports keeping only the destinations to any measure of size, but only for firms exporting little, which is the most relevant one from the theory perspective.

${ }^{35}$ It can be shown that our theory results carry over to this approximation of export concentration. Details available upon request. 

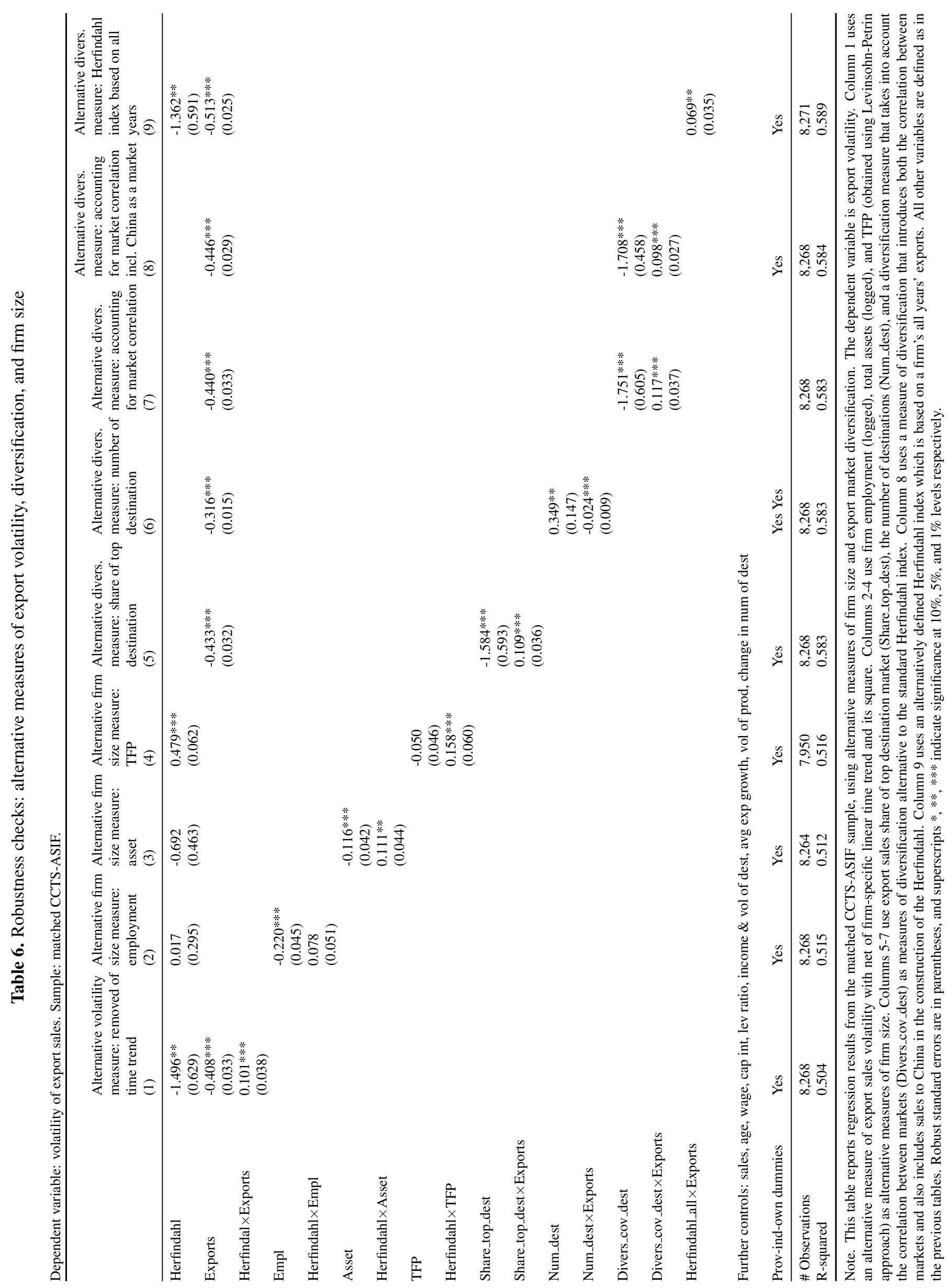
which a firm continuously exports or to which it exports again after having stopped. In other words, we disregard the destinations to which a firm exports in successive years for less than seven years. The rationale is that, if a firm observes bad long-run demand conditions for its product (i.e. a low $\chi_{j i}$ as described in Section 3.4.1, it should not re-enter after exiting that market. By keeping markets to which a firm first had a sequence of positive sales, zero sales, positive sales again, we should capture the firms which are in line with the description of Section 3.3.2. ${ }^{36}$ The result, reported in Column 1 of Table 6, is similar to the baseline specification, suggesting that the observed relationship between volatility and diversification is not driven by the experimentation motive. These results, together with the facts that the results hold when excluding markets to which firms export only one year (Columns 4 of Table 5) make us confident that the market experimentation channel does not drive the results.

\subsubsection{Accounting for entrants and exiters}

Our baseline sample only includes continuous exporters that export in all the 7 years of the sample period (i.e. 6 observations of growth rates). As argued in Section 2.1, we make this choice to ensure that our volatility measure is based on a sufficient number of observations. If the firms that do not export permanently are smaller, less diversified and more volatile, ${ }^{37}$ however, the patterns that we observe may be due to a sample selection bias. These concerns give rise to a trade-off between measurement error and sample selection bias, which we now study in more details. For this, we investigate in Table 7 whether our baseline results are robust to alternative samples that include both continuous exporters and entrants/exiters. In Columns 2-4, we add to our baseline sample of continuous exporters all firms which exported for less than 7 years in the sample period but have export growth rates defined for at least 6 , 5, and 4 years, respectively. For example, if a firm exports in all years except 2003 and 2004, its export growth rates can be calculated for 2003 (in which case it is -2) and 2005 (+2) but not for 2004 . We therefore observe 5 years of growth rates for that firm which would enter the sample of Column 3, with a volatility equal to the variance of these 5 growth rates. Column 2 differs from our baseline specification because it contains firms which export in 6 out of the 7 years, but for which we can still compute 6 years of growth rates since we use the mid-point growth rate. Note that the Herfindahl index and exports are

\footnotetext{
${ }^{36}$ Note that we are taking a more restrictive approach than suggested by our theory. From Section 3.4, if a firm sees poor demand conditions on a market, it sells only one year there. In practice, obtaining the information about $\chi_{j i}$ may take more time, which is why a firm may export two or three years before realizing it should definitely exit. With this strategy, we also exclude markets to which the firm enters and starts selling continuously, thereby partialing out the role of growth in the set of markets more generally.

${ }^{37}$ Firms which do not export permanently are indeed smaller than continuous exporters. We measure their size as their exports in the first year in which they export and find that their average log exports are equal to 14.9 in the matched sample against 16.3 for continuous exporters. The Herfindahl of export destinations is however almost between firms which do not export in all 7 years $(0.69)$ and those who do $(0.66)$.
} 
constructed using the initial year in which the firm started exporting and thus is not necessarily the year of 2000 as was in the baseline sample. The coefficient of the interaction between the firm size and the Herfindahl index remains positive and significant. Our estimates when incorporating firms that enter and/or exit the export market during the sample period are both qualitatively and quantitatively similar to our baseline results.

\subsubsection{Excluding exports to Hong Kong}

Our computation of the Herfindahl index and other diversification measures treats Hong-Kong as an individual export destination. However, firms may use Hong Kong as an export platform and re-export to other destinations, so the true level of diversification is not precisely measured. More than classical measurement error, exports to Hong Kong may introduce a bias if firms using Hong Kong as a platform are systematically different in terms of size. To check if the inclusion of exports to Hong Kong affects our results, we re-estimate our baseline regression in Columns 5 and 6 based on an alternative samples in which we only keep those firms that sell respectively less than $10 \%$ of their exports to Hong Kong or none of their exports to Hong Kong. Again, the coefficient of the interaction term and the Herfindahl index is relatively stable across specifications and has the expected sign. Finally, we exclude exports to Hong Kong for each firm, then re-calculate the Herfindahl index and the firm size measures, and re-estimate the baseline regressions. The results are reported in Column 7, which are, again, generally consistent with other regressions. Overall, the above exercises ensure that our main results are robust to alternative treatments of exports to Hong Kong.

\subsubsection{Additional robustness checks}

Finally, in Column 8, we also recompute the Herfindahl index of each firm's exports based not on the countries to which it exports but on seven groups of countries: the European Union, NAFTA, ASEAN, Australia, other OECD countries, Africa, and the rest of the world. This exercise addresses the concern that demand shocks across markets are unlikely to be independent, in particular in neighboring countries. Again, the results are qualitatively very similar to our baseline estimates. In Column 9, we exclude firms which exported to only one market (i.e. with a Herfindahl index of one) in our sample. Excluding these firms ensures that our baseline results are not driven by the differences between these single-market firms whose Herfindahl index is one, and the multi-market exporters whose Herfindahl index is less than one. Unreported robustness checks also show that our results are robust to using different definitions of growth rates and thresholds for the exclusion of outliers, with no changes to our conclusions. 


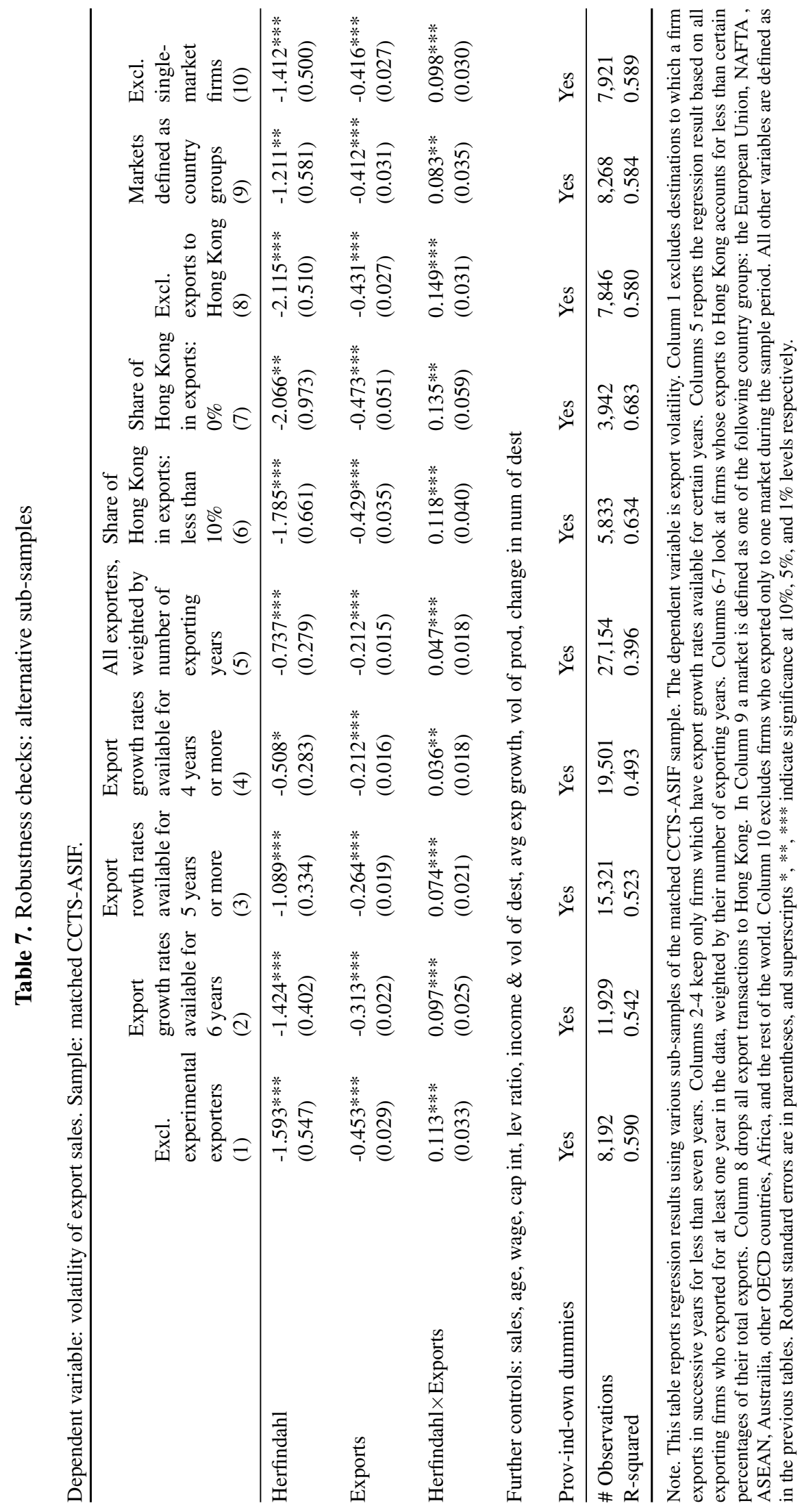




\subsection{Reverse causality and instrument variable estimation}

Our theory assumes that causality runs from the diversification of exports across markets to the volatility of exports. In the simple framework of Section 3, firms do not choose their exposure to different markets and they maximize profits with no consideration for volatility. In reality, however, causality may run from volatility to diversification. Consider a firm selling a product with a very volatile demand. As long as demand shocks are not perfectly correlated across markets, a risk-averse or financially-constrained firm may wish to diversify its sales across destinations to stabilize its exports, giving rise to a positive link between diversification and volatility. To the extent that large firms are less sensitive to volatility (e.g. because they are less financially constrained), this reverse causality may be dampened for larger firms, generating the observed positive coefficient on our interaction term. A number of reasons makes us think that reverse causality is unlikely to drive our results. First, we include in our regressions many balance sheet items, a rich set of industry and province fixed effects, as well as controls for the volatility of the destinations to which the firm exports and the volatility of the product-mix of the firms exports. We thereby control for any systematic difference in volatility due to these observable characteristics. Second, in all the regressions we use firms initial period value of total exports and of the Herfindahl index, which should be less subject to reverse causality, as beginning of period size and diversification are less likely to depend on subsequent volatility.

Finally, we address the issue of reverse causality more directly by constructing a firm-specific instrument for the concentration of exports. ${ }^{38}$ We construct it in two steps. First, we calculate for each 6-digit product a measure of the concentration of world demand for Chinese exports, i.e. we construct using our CCTS data a nationwide Herfindahl index for each product based on the share of each destination in the Chinese exports of that product. Second, we compute for each firm a weighted average of these product-specific Herfindahl indices, where the weights reflect the share of each product in the firm's exports in 2000. This gives us a firm-specific predicted Herfindahl index based on the concentration of exports at the national level. We use as instruments this predicted Herfindahl index and its interaction with the size of the firm's exports. The exclusion restriction behind our strategy is that the predicted Herfindahl index based on national export patterns is not directly related to the volatility of a firm's export volatility but only influences it through the firm's own export concentration. Since some firms in our sample may account for a large share of Chinese exports in a product, there may be a concern that the national measures of diversification are directly influenced by firm-level diversification for some

\footnotetext{
${ }^{38}$ We thank an anonymous referee for suggesting this instrument.
} 
Table 8. Instrument variable estimations

Dependent variable: volatility of export sales. Sample: matched CCTS-ASIF.

\begin{tabular}{|c|c|c|c|c|}
\hline & \multicolumn{4}{|c|}{$\begin{array}{l}\text { IV for Herfindahl index: diversification of } \\
\text { world demand for Chinese products }\end{array}$} \\
\hline & $\begin{array}{l}\text { All firms } \\
\text { (1) }\end{array}$ & $\begin{array}{l}\text { All firms } \\
(2)\end{array}$ & $\begin{array}{l}\text { Firms whose share } \\
\text { in China's exports } \\
\text { is less than } 5 \% \\
\text { for any product } \\
\text { (3) }\end{array}$ & $\begin{array}{l}\text { Firms whose share } \\
\text { in China's exports } \\
\text { is less than } 5 \% \\
\text { for any product } \\
\text { (4) }\end{array}$ \\
\hline Herfindahl & $\begin{array}{l}-8.116 * * \\
(3.245)\end{array}$ & $\begin{array}{l}-7.255^{* *} \\
(3.538)\end{array}$ & $\begin{array}{l}-16.686 * * * \\
(6.175)\end{array}$ & $\begin{array}{l}-16.137 * * \\
(6.429)\end{array}$ \\
\hline Exports & $\begin{array}{l}-0.686^{* * *} \\
(0.144)\end{array}$ & $\begin{array}{l}-0.690 * * * \\
(0.166)\end{array}$ & $\begin{array}{l}-1.119 * * * \\
(0.290)\end{array}$ & $\begin{array}{l}-1.135 * * * \\
(0.312)\end{array}$ \\
\hline Herfindahl $\times$ Exports & $\begin{array}{l}0.472 * * \\
(0.186)\end{array}$ & $\begin{array}{l}0.411^{* *} \\
(0.197)\end{array}$ & $\begin{array}{l}0.993 * * * \\
(0.366)\end{array}$ & $\begin{array}{l}0.947 * * \\
(0.373)\end{array}$ \\
\hline
\end{tabular}

Further controls: sales, age, wage, cap int, lev ratio, income \& vol of dest, avg exp growth, vol of prod, change in num of dest

\begin{tabular}{lllll} 
Further controls & No & Yes & No & Yes \\
Prov-ind-own dummies & Yes & Yes & Yes & Yes \\
\hline \# Observations & 6,608 & 6,575 & 4,796 & 4,771 \\
R-squared & 0.179 & 0.231 & 0.036 & 0.106 \\
Underidntification LM p-value & 0.000 & 0.000 & 0.000 & 0.000 \\
Kleibergen-Paap F statistic & 43.048 & 29.484 & 18.276 & 13.833 \\
\hline
\end{tabular}

Note. This table reports the second-stage regression results using instrumental variable approach. The dependent variable is export volatility. The endogenous variables are Herfindahl index and its interaction with exports. The main instrument variable is the firm-level weighted average of the world demand diversification (Herfindahl index) of the products it exports, with the weight being the share of each product in its total export sales, based on its initial year data. This measure is also interacted with exports as an instrument for the interaction of Herfindahl index with exports. World demand is defined as other countries' demand for Chinese products. All other variables are defined as in the previous tables. Robust standard errors are in parentheses, and superscripts $*, * *, * * *$ indicate significance at $10 \%, 5 \%$, and $1 \%$ levels respectively.

firm-product pairs. We therefore also run our analysis excluding any firm accounting for more than 5\% of the Chinese exports of a product. We report the first-stage estimates in the Appendix Table A3 and present the second-stage results in Table 8. Columns 1 and 2 show the results for the whole sample while Columns 3 and 4 only look at firms accounting for less than 5\% of Chinese sales for all products. The instruments are quite strong, with F-tests typically well above 10, and the coefficients of interests in the second stage show the same qualitative patterns as in our baseline, although the coefficients are typically much higher than with OLS. This gives us some additional confidence that we actually capture a causal effect of export concentration on the volatility of exports. 


\section{Conclusions}

The contribution of this paper is twofold. First, we show that, in a large sample of Chinese exporters from 2000 to 2006, the geographic diversification of exports is positively associated with volatility among small exporters while the relationship is negative among large exporters. These results, which stand in marked contrast to standard portfolio theory for small exporters, are robust to a wide array of controls. Second, we develop a simple model to explain these empirical patterns. We show in a setup featuring idiosyncratic destination-specific demand shocks and fixed costs of exports per country that selling occasionally to a destination raises the volatility of exports. The model predicts that, among small exporters, the geographic diversification of exports is associated with a higher fraction of exports going to a destination where the firm sells occasionally, thereby raising export volatility. This channel provides a counteracting force to the standard diversification argument and can even overturn it, giving rise to a negative link between the Herfindahl index of exports and export volatility. Our empirical analysis provides strong evidence that this channel is the main driver of the observed empirical patterns, and that the conclusions are unlikely to be driven by other channels such as experimenting on foreign markets or reverse causality.

\section{References}

Albornoz, Facundo, Héctor F. Calvo Pardo, Gregory Corcos, and Emanuel Ornelas (2012), "Sequential exporting," Journal of International Economics, 88(1), 17-31.

Alessandria, Georges, Joseph Kaboski, and Virgiliu Midrigan (2010), "Inventories, lumpy trade, and large devaluations," American Economic Review, 100(5), 2304-2339.

Arkolakis, Costas (2010), "Market penetration costs and the new consumers margin in international trade," Journal of Political Economy, 118(6), 1151-1199.

Baum, Christopher, Mustafa Caglayan, and Oleksandr Talavera (2013), "R\&D expenditures and geographical sales diversification," Mimeo.

Bejan, Maria (2006), “Trade openness and output volatility,” MPRA Working paper 2759.

Besedes, Tibor and Thomas Prusa (2011), "The role of extensive and intensive margins and export growth," Journal of Development Economics, 96(2), 371-379. 
Bricongne, Jean Charles, Lionel Fontagné, Guillaume Gaulier, Daria Taglioni, and Vincent Vicard (2012), "Firms and the global crisis: French exports in the turmoil," Journal of International Economics, 87(1), 134-146.

Buch, Claudia, Joerg Doepke, and Kerstin Stahn (2009a), "Great moderation at the firm level? Unconditional vs. conditional output volatility," The B.E. Journal of Economic Analysis and Policy, 9(1).

Buch, Claudia, Joerg Doepke, and Harald Strotmann (2009b), “Does export openness increase firm-level output volatility?" The World Economy, 32, 531-551.

Caselli, Francesco, Miklos Koren, Milan Lisicky, and Silvana Tenreyro (2014), "Diversification through trade," Mimeo.

Davis, Steven, John Haltiwanger, Ron Jarmin, and Javier Miranda (2006), "Volatility and dispersion in business growth rates: publicly traded versus privately held firms," NBER Macroeconomics Annuals, $21,107-180$.

di Giovanni, Julian and Andrei Levchenko (2009), "Trade openness and volatility,” Review of Economics and Statistics, 91(3), 558-585.

di Giovanni, Julian, Andrei Levchenko, and Isabelle Méjean (2014), "Firms, destinations and aggregate fluctuations," Econometrica, 82(4), 1303-1340.

Easterly, William, Roumeen Islam, and Joseph Stiglitz (2001), "Shaken and stirred: explaining growth volatility," in Annual World Bank conference on development economics, ed. by B. Pleskovic and N.Stern, World Bank, 191-211.

Eaton, Jonathan, Samuel Kortum, and Francis Kramarz (2011), "An anatomy of international trade: evidence from French firms," Econometrica, 79(5), 1453-1498.

Garcia-Vega, Maria, Alessandra Guariglia, and Marina-Eliza Spaliara (2012), "Volatility, financial constraints, and trade," International Review of Economics and Finance, 21(1), 57-76.

Haddad, Mona, Jamus Lim, Cosimo Pancaro, and Christian Saborowski (2013), "Trade openeness reduces growth volatility when countries are well diversified," Canadian Journal of Economics, 46(2), $765-790$.

Hirsch, Seev and Baruch Lev (1971), "Sales stabilization through export diversification," Review of Economics and Statistics, 53(3), 270-277. 
Hornok, Cecilia and Miklós Koren (2015), "Per-shipment costs and the lumpiness of international trade," Review of Economics and Statistics, 97(2), 525-530.

Hsieh, Chang-Tai and Ralph Ossa (2011), “A global view of productivity growth in China,” NBER Working Paper 16778.

Impullitti, Giammario, Alfonso Irarrazabal, and Luca Opromolla (2013), "A theory of entry into and exit from export markets," Journal of International Economics, 90(1), 75-90.

Irarrazabal, Alfonso and Luca Opromolla (2009), “The cross sectional dynamics of heterogeneous trade models," Banco de Portugal Working paper 24-2009.

Juvenal, Luciana and Paulo Monteiro (2013), "Export market diversification and productivity improvement: theory and evidence from Argentinian firms," Federal Reserve Bank of Saint Louis Working Paper 2013-015A.

Kelly, Bryan, Hanno Lustig, and Stijn Van Nieuwerburgh (2013), "Firm volatility in granular networkds," Mimeo.

Koren, Miklos and Silvana Tenreyro (2007), "Volatility and development," Quarterly Journal of Economics, 122(1), 243-287.

Kramarz, Francis, Julien Martin, and Isabelle Méjean (2015), "Volatility in the Small and in the Large: Diversification in Trade Networks," Working Paper.

Kropf, Andreas and Philip Sauré (2014), "Fixed costs per shipment," Journal of International Economics, 92(1), 166-184.

Kurz, Christopher and Mine Senses (2016), "Importing, exporting and firm-level employment volatility," Journal of International Economics, 98, 160-175.

Lileeva, Alla and Daniel Trefler (2010), "Improved access to foreign markets raises plant-level productivity... for some plants," Quarterly Journal of Economics, 125(3), 1051-1099.

Newbery, David and Josef Stiglitz (1984), "Pareto inferior trade," Review of Economic Studies, 51(1), $1-12$.

Ramey, Garey and Valerie Ramey (1995), "Cross-country evidence on the link between volatility and growth," American Economic Review, 85(5), 1138-1151. 
Rodrik, Dani (1998), "Why do more open economies have bigger governments?" Journal of Political Economy, 106(5), 997-1032.

Shaver, J. Myles (2011), "The benefits of geographical sales diversification: how exporting facilitates capital investment," Strategic Management Journal, 32(10), 1046-1060.

UN (2011), “Towards human resilience: sustaining MDG progress in an age of economic uncertainty," United Nations Development Programme.

Upward, Richard, Zheng Wang, and Jinghai Zheng (2013), “Weighing China's export basket: the domestic content and technology intensity of Chinese exports," Journal of Comparative Economics, 41(2), 527-543.

Vannoorenberghe, Gonzague (2012), "Firm-level volatility and exports," Journal of International Economics, 86(1), 57-67.

Wagner, Joachim (2014), "Is export diversification good for profitability? First evidence for manufacturing enterprises in Germany," University of Lueneburg WP Economics 297.

Wang, Zheng and Zhihong Yu (2012), “Trading partners, traded products and firm performances of Chinas exporter-importers: does processing trade make a difference?" The World Economy, 35(12), $1795-1824$. 


\section{Appendix A Appendix}

\section{A.1 Theory appendix}

\section{A.1.1 Approximation of volatility}

Our model structure guarantees that, for any firm, $E\left(\omega_{j i t} g_{j i t}\right)=0$ on both markets and $E\left(g_{j t}\right)=0$ for all $j$. The variance of the growth rate of exports $V_{j}$ is thus exactly given by:

$$
V_{j}=E\left[\left(\omega_{j 1 t} g_{j 1 t}+\omega_{j 2 t} g_{j 2 t}\right)^{2}\right]
$$

where $E$ refers to the expectation over time. We now make the following approximation:

$$
\omega_{j i t} \approx \frac{x_{j i t}+x_{j i t-1}}{2 x_{j}}
$$

where $x_{j}$ is some time-invariant measure of the size of the firm's exports. With this approximation, we neglect the fact that the share of exports going to one market depends on the exports to the other market. Combined with the assumption of independent shocks, we can rewrite:

$$
V_{j}=E\left[\omega_{j 1 t}^{2} g_{j 1 t}^{2}\right]+E\left[\omega_{j 2 t}^{2} g_{j 2 t}^{2}\right]
$$

Using (6) in (24) shows that, if $j$ exports continuously to $i$, our approximation of $\omega_{j i t}$ equals:

$$
\omega_{j i t}=\left\{\begin{array}{rr}
\sigma \lambda_{j i} \underline{s} / x_{j} & \text { with prob. 1/4 } \\
\sigma \lambda_{j i}(\underline{s}+\bar{s}) / 2 x_{j} & \text { with prob. 1/2 } \\
\sigma \lambda_{j i} \bar{s} / x_{j} & \text { with prob. 1/4 }
\end{array}\right.
$$

In this market, growth is positive and equal to $2 \sqrt{\mu}$ if the past shock was $\underline{s}$ and the current shock is $\bar{s}$, which occurs with probability $1 / 4$. Similarly, growth is negative and equal to $-2 \sqrt{\mu}$ if the shock goes from $\bar{s}$ to $\underline{s}$. In both other cases, growth is zero. We therefore obtain:

$$
E\left[\omega_{j i t}^{2} g_{j i t}^{2}\right] \approx \frac{1}{2} \frac{\sigma^{2} \lambda_{j i}^{2}(\bar{s}+\underline{s})^{2}}{4 x_{j}^{2}} 4 \mu .
$$

If we define $\omega_{j i}=E\left[\omega_{j i t}\right]=E\left[x_{j i t}\right] / E\left[x_{j t}\right]$, i.e. as the share of market $i$ in the total sales of the firm over the period, we obtain from (27) that $E\left[\omega_{j i t}^{2} g_{j i t}^{2}\right]=2 \mu \omega_{j i}^{2}$ and (16) follows. If we define the share of market $i$ in $j$ 's exports as $\omega_{j i}=x_{j i 0} / x_{j 0}$, which is our benchmark measure, equation (27) implies that $E\left[\omega_{j i t}^{2} g_{j i t}^{2}\right]=2 \mu \omega_{j i}^{2}((\bar{s}+\underline{s}) / 2 \bar{s})^{2}$ with probability $1 / 2$ and $E\left[\omega_{j i t}^{2} g_{j i t}^{2}\right]=2 \mu \omega_{j i}^{2}((\bar{s}+\underline{s}) / 2 \underline{s})^{2}$ with probability $1 / 2$.

On a market where firms export occasionally, the market has a weight zero with probability 1/4 (for two consec- 
utive years of low demand $\underline{s}$ ), a growth of zero with probability $1 / 4$ (two consecutive draws of $\bar{s}$ ), a growth of 2 with prob. $1 / 4$ and a growth of -2 with prob. $1 / 4$. The contribution of that market to the variance of exports is, using our approximation:

$$
E\left[\omega_{j i^{\prime} t}^{2} g_{j i^{\prime} t}^{2}\right]=2 \frac{\left(\sigma \lambda_{j i^{\prime}} \bar{s}\right)^{2}}{4 x_{j}^{2}}
$$

This can easily be shown to equal $2 \omega_{j i^{\prime}}$ if $\omega_{j i^{\prime}}=E\left[x_{j i^{\prime}}\right] / E\left[x_{j t}\right]$, which confirms equation (19).

\section{A.1.2 Derivation of equation (13)}

The Herfindahl index is defined as:

$$
\operatorname{Herf}_{j}=\frac{x_{j 1}^{2}+x_{j 2}^{2}}{\left(x_{j 1}+x_{j 2}\right)^{2}}
$$

Totally differentiating:

$$
d \operatorname{Herf}_{j}=2 x_{j}^{-3}\left(x_{j 1}-x_{j 2}\right)\left(d x_{j 1} x_{j 2}-d x_{j 2} x_{j 1}\right) .
$$

Similarly, totally differentiating the volatility in (11) and assuming that $\partial V A R_{j i} / \partial x_{j m}=0$ for $i \neq m$ gives:

$$
d V_{j}=2 x_{j}^{-3}\left(d x_{j 1} x_{j 2}-d x_{j 2} x_{j 1}\right)\left(x_{j 1} V A R_{j 1}-x_{j 2} V A R_{j 2}\right)+d x_{j 1}\left(\frac{x_{j 1}}{x_{j}}\right)^{2} \frac{\partial V A R_{j 1}}{\partial x_{j 1}}+d x_{j 2}\left(\frac{x_{j 2}}{x_{j}}\right)^{2} \frac{\partial V A R_{j 2}}{\partial x_{j 2}} .
$$

Rewriting:

$d x_{j 1}\left(\frac{x_{j 1}}{x_{j}}\right)^{2} \frac{\partial V A R_{j 1}}{\partial x_{j 1}}=d x_{j 1}\left[\left(\frac{x_{j 1}}{x_{j}}\right)^{3} \frac{\partial V A R_{j 1}}{\partial x_{j 1}}+\frac{x_{j 2}}{x_{j}}\left(\frac{x_{j 1}}{x_{j}}\right)^{2} \frac{\partial V A R_{j 1}}{\partial x_{j 1}}+\left(\frac{x_{j 2}}{x_{j}}\right)^{3} \frac{\partial V A R_{j 2}}{\partial x_{j 2}}-\left(\frac{x_{j 2}}{x_{j}}\right)^{3} \frac{\partial V A R_{j 2}}{\partial x_{j 2}}\right]$,

and a similar expression for market 2, using $d x_{j}=d x_{j 1}+d x_{j 2}$ and plugging (30) in (31) gives (13).

\section{A.1.3 Volatility in the dynamic case}

We here consider the case of a firm exporting continuously to market 1 but just exploring market 2 . In other words, over $\mathrm{T}$ periods, the firm enters market 2 at $t$ (with a growth of +2 ) and exits the market at $t+1$ (with a growth of -2). Let us denote the amount sold in period $t$ as $x_{j 2 t}$. If we define $\omega_{j 2}$ as the share of sales going to market 2 over the $\mathrm{T}$ periods, it implies that:

$$
\omega_{j 2}=\frac{x_{j 2 t}}{T x_{j}}
$$

The contribution of that market to the variance of exports is, during a fraction $2 / \mathrm{T}$ of the periods, coming from the entry and exit, while it is zero for all other periods. Using our approximation:

$$
E\left[\omega_{j 2 t}^{2} g_{j 2 t}^{2}\right]=\frac{2}{T} \frac{x_{j 2 t}^{2}}{X_{j}^{2}}=2 T \omega_{j 2}^{2}
$$

A firm exporting continuously to market 1 and only entering and exiting market 2 therefore has a volatility (using 
$\bar{\omega}_{j 2}=1-\bar{\omega}_{j 1}$ and $\left.\omega_{j 1}=1 / 2+1 / 2 \sqrt{2 \operatorname{Herf}_{j}-1}\right)$ :

$$
V^{D}=(\mu+T) \operatorname{Herf}_{j}-(T-\mu) \sqrt{2 \operatorname{Herf}_{j}-1}
$$

which is decreasing in $\operatorname{Herf}_{j}$ for large enough $\mathrm{T}$ and is very similar to $V^{O}$ in equation (19). To be clear about the mechanism, consider $\underline{s}=\bar{s}$, i.e. the firm sells in each period the same amount on its continuous export market $(\mu=0)$. In one year, it explores a second market and sells a positive amount there before realizing that it is not worth selling further on that market. The one-time export to a market creates a variation in total exports, which therefore raises the volatility and also makes the Herfindahl index lower than one. This makes explicit that a negative correlation between the Herfindahl index and volatility can arise even in the absence of short-run shocks when the Herfindahl is based on the average sales to a market over time. This speaks for using the exports computed in the first year as in our baseline regressions instead of the average exports over the period to compute the Herfindahl index.

\section{A.1.4 The theory's implications for the empirical link between diversification, size and volatility}

As shown in Section 3.3, the model implies that firms exporting occasionally to a market may have more volatile exports than firms selling continuously to both markets. Since small exporters are more likely to export occasionally (as confirmed empirically by Figure 2), we argue that this may account for the observed relationship between volatility, diversification and size. The aim of this section is to formalize and qualify these insights.

As stated in the main analysis, for a given Herfindahl index, the volatility of an occasional exporter is smaller than the volatility of a permanent exporter. Furthermore:

$$
\begin{aligned}
\frac{\partial V_{j}^{C}}{\partial \operatorname{Herf}_{j}} & =2 \mu, \\
\frac{\partial V_{j}^{O}}{\partial \operatorname{Herf}_{j}} & =1+\mu-\frac{1-\mu}{\sqrt{2 H e r f_{j}-1}}<2 \mu
\end{aligned}
$$

where the inequality obtains because, in our simple setup, $\operatorname{Her} f_{j}>1 / 2$. An increase in the Herfindahl index has a positive effect on the volatility of exports among continuous exporters to both markets, but a smaller effect among firms which export occasionally to one of the markets, i.e. $\partial V_{j}^{C} / \partial H e r f_{j}>\partial V_{j}^{O} / \partial H e r f_{j}$. For a small enough Herfindahl, and as illustrated in Figure A1, an increase in the Herfindahl index can even decrease volatility.

The expected volatility of sales conditional on the size and Herfindahl of exports - which is the main object of the empirical analysis — is, in our model, given by:

$$
E[V \mid \operatorname{Herf}, X]=P^{C}(\operatorname{Herf}, x) V^{C}(\operatorname{Herf})+\left(1-P^{C}(\operatorname{Herf}, x)\right) V^{O}(\operatorname{Herf}),
$$



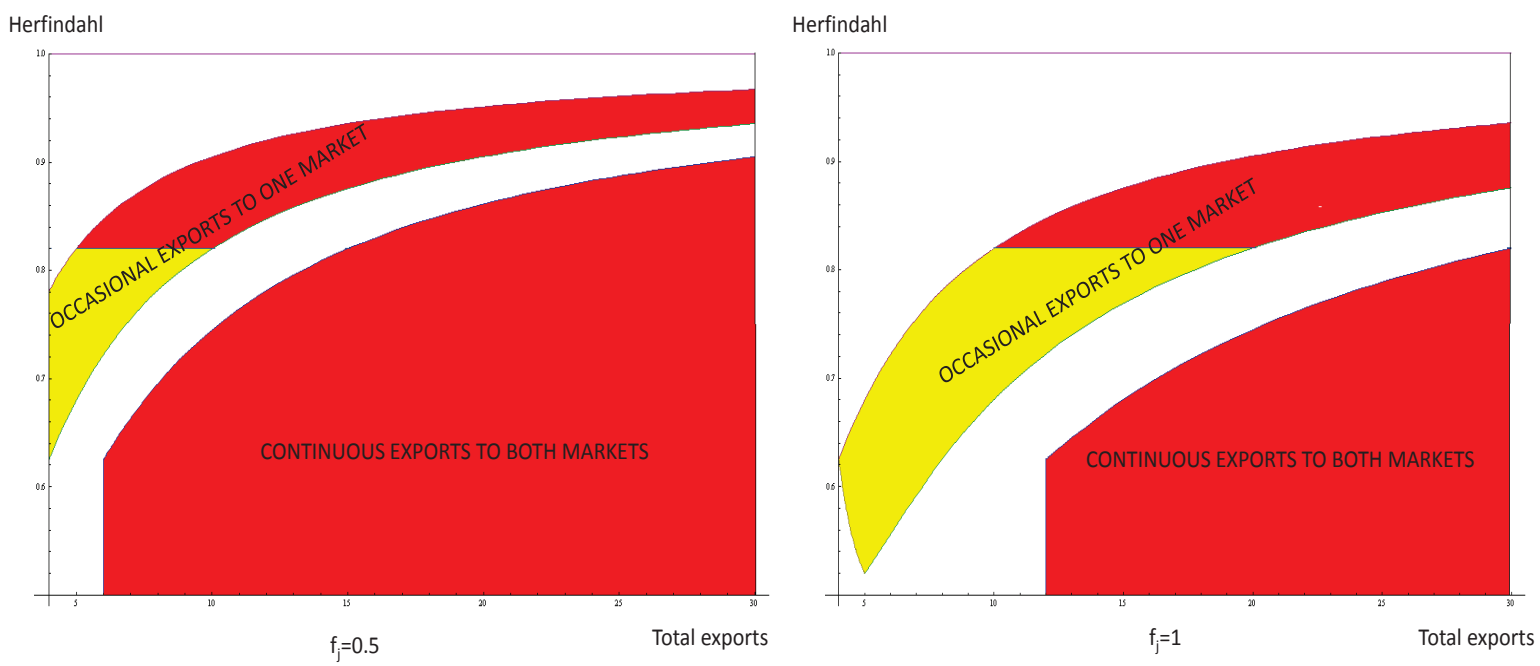

Figure A1. Range of continuous and occasional exporters. The figures shows the range of $\{H, X\}$ for which firms are continuously exporting to both markets or occasionally exporting to one of the market. The left panel assumes lower fixed costs of exports $(f=0.5)$ than the right panel $(f=1)$. The red area corresponds to the $\{H, X\}$ combinations for which $\mathrm{d} V_{j} / \mathrm{d} H \operatorname{Herf} f_{j}>0$ while in the yellow area: $\mathrm{d} V_{j} / \mathrm{d} H \operatorname{Her} f_{j}<0$.

where $V^{C}($ Herf $)$ and $V^{O}($ Herf $)$ are defined by (16) and (19) respectively and where $P^{C}($ Herf, $x)$ is the probability that a firm continuously exports to both markets conditional on an $\{x, \operatorname{Herf}\}$ combination $\left(1-P^{C}(\operatorname{Herf}, x)\right)$ is the probability that it exports occasionally to one of the markets). To shorten the notation, we leave out the conditionality in the following and refer to $E[V \mid \operatorname{Her} f, x]$ as $E[V]$. The three main comparative statics of interest for our analysis are:

$$
\begin{aligned}
\frac{\partial E[V]}{\partial x} & =\frac{\partial P^{C}}{\partial x}\left(V^{C}(\text { Herf })-V^{O}(\text { Herf })\right), \\
\frac{\partial E[V]}{\partial H e r f} & =\frac{\partial P^{C}}{\partial \operatorname{Herf}}\left(V^{C}(\text { Herf })-V^{O}(\text { Herf })\right)+P^{C} \frac{\partial V^{C}(\text { Herf })}{\partial H e r f}+\left(1-P^{C}\right) \frac{\partial V^{O}(\text { Herf })}{\partial H e r f}, \\
\frac{\partial^{2} E[V]}{\partial \operatorname{Herf} \partial x} & =\frac{\partial^{2} P^{C}}{\partial \operatorname{Herf} \partial x}\left(V^{C}(\text { Herf })-V^{O}(\text { Herf })\right)+\frac{\partial P^{C}}{\partial x}\left(\frac{\partial V^{C}(\text { Herf })}{\partial \operatorname{Herf}}-\frac{\partial V^{O}(\text { Herf })}{\partial \operatorname{Herf}}\right),
\end{aligned}
$$

which make explicit the central role played by the function $P^{C}$. Our intuitive reasoning at the end of Section 3.3 relies on the idea that $\partial P^{C} / \partial x \geq 0$ (i.e. the fraction of firms exporting continuously to both markets is larger among firms with large total exports) - which we illustrate in Figure 2 - and neglects the dependence of $P^{C}$ on Herf (i.e. neglects the first term on the right hand side of (39) and (40)). Assuming that this is the case, it immediately implies that (i) $E[V]$ is decreasing in $x$, (ii) the interaction term $\left(\partial^{2} E[V] /(\partial x \partial H e r f)\right)$ is positive and (iii) if, for small $x, P^{C}$ is small enough and $\partial V^{O} / \partial \operatorname{Herf}<0$, the Herfindahl index has a negative effect on the volatility of exports for small exporters. These three results are in line with the baseline outcome of the empirical analysis $\left(\partial E[V] / \partial x<0, \partial E[V] / \partial H<0\right.$ for $x$ small and $\left.\partial^{2} E[V] / \partial H \partial x>0\right)$.

We now characterize the function $P^{C}(\operatorname{Herf}, x)$ to assess the plausibility of the above assumptions. For simplicity, we consider in the following a definition of the Herfindahl index and on the size of exports based on the total sales 
above all years (i.e. $x_{j}=\sum_{i} E\left[x_{j i t}\right]$ and $\omega_{j i}=E\left[x_{j i t}\right] / x_{j}$.). The reasoning extends to a case where these are defined as the values in the first year of the sample but at the cost of some additional complexity. ${ }^{39}$ Consider now that firm $j$ has a given fixed cost of exporting $f_{j}$ (see Lileeva and Trefler (2010)). Firm $j$ exports continuously to both markets if: $\lambda_{j i \underline{s}}>f_{j}$, implying that the total exports of firm $j$ are $x_{j}>\sigma\left(\frac{\bar{s}}{\underline{s}}+1\right) f_{j}$. Furthermore, given $x_{j}$, firm $j$ must have a small enough Herfindahl index $\operatorname{Herf}_{j}<\tilde{H}(1+\bar{s} / \underline{s})$ where:

$$
\tilde{H}(y)=\frac{1}{2}+\frac{1}{2}\left(1-\sigma \frac{f_{j}}{x_{j}} y\right)^{2}
$$

Similarly, if firm $j$ exports continuously to market $i$ but occasionally to market $i^{\prime}$, its size is at least equal to $x_{j}>\sigma f_{j}\left(1+\frac{\bar{s}}{2 \underline{s}}\right)$ and the Herfindahl index of exports must be such that $\tilde{H}(1+\bar{s} / \underline{s})<\operatorname{Her} f_{j}<\tilde{H}(1)$ if $x_{j}<$ $\sigma f_{j}(\bar{s} / \underline{s}+1 / 2)$ and $\tilde{H}(\bar{s} / \underline{s})<\operatorname{Her} f_{j}<\tilde{H}(1)$ otherwise. We plot in Figure A1 the admissible values of $x_{j}$ and of $\operatorname{Herf}_{j}$ for two different levels of the fixed costs of exports. For a given $f_{j}$, the combination of $\left\{x_{j}, H e r f_{j}\right\}$ fully determines whether a firm is a continuous exporter to both markets $\left(P^{C}=1\right)$ or occasionally exports to one market $\left(P^{C}=0\right)$. It also appears that some combinations of $\left\{x_{j}, \operatorname{Her} f_{j}\right\}$ cannot be observed for a given fixed costs level (in white, $P^{C}$ undefined). Figure A1 confirms that, for a given Herfindahl index, larger exporters are more likely to continuously export on both markets. It also shows that, for a given $x$, firms with larger Herfindahl index are more likely to be occasional exporters to one market.

Although the function $P^{C}(\operatorname{Herf}, x)$ as depicted in Figure A1 exhibits a discrete jump and is undefined for a large range of $\{\operatorname{Herf}, x\}$ combinations, it should be noted that some degree of firm-level heterogeneity between the fixed costs of exports ${ }^{40}$ or the presence of more than two markets would shrink the inadmissible (white) range and smoothen the function $P^{C}(\operatorname{Her} f, x)$. We show in a number of unreported simulations for a wide range of plausible values that $\partial P^{C} / \partial x \geq 0$ while $\partial P^{C} / \partial H e r f$ and the cross partial $\partial^{2} P^{C} / \partial x \partial H e r f$ depend on the particular distributional assumptions. Note that in our sample of Chinese exporters, it appears from Table 2 that $\partial P^{C} / \partial \operatorname{Herf}>0$ and $\partial^{2} P^{C} / \partial x \partial H \operatorname{Herf}<0$, which contribute to make (39) negative and (40) positive, i.e. to generate the empirically observed coefficients.

Since $\partial P^{C} / \partial H e r f$ and $\partial^{2} P^{C} / \partial x \partial H e r f$ have an ambiguous sign in theory, we complement the analysis with a simulation of the model to show that it can replicate the empirical patterns for plausible distributions of the parameters. ${ }^{41}$ We should emphasize that it does not necessarily generate such patterns, but that it can under reasonable assumptions. Second, we simulate an extended version of our model to five export markets to show

\footnotetext{
${ }^{39}$ Two firms with the same average sales to each market do not have the same sales to each market every year due to the randomness of $\zeta_{j i t}$. Adding this uncertainty blurs Figure A1 a bit but does not change its message when imposing a very weak additional condition on the distribution of parameters. Details available upon request.

${ }^{40}$ For example, if $50 \%$ of firms have $f=1$ and $50 \%$ have $f=0.5$, this means superimposing both parts of Figure A1. The size of the white range shrinks, and the discrete jump in $P^{C}$ disappears as some range of the $\{\operatorname{Herf}, x\}$ now admits intermediate values of $P^{C}$.

${ }^{41}$ We need to look at simulations due to the complexity of the function $P^{C}$, which depends on the distribution of (i) productivity $(\varphi)$, (ii) firm-level demand $\chi_{j i}$ on each market, and (iii) export fixed costs $\left(f_{j}\right)$ if these are heterogeneous across firms.
} 
that the intuition of our two market case readily extends to a setup with more markets.

We follow Eaton et al. (2011) and Hsieh and Ossa (2011) in assuming that the distribution of productivity $(\varphi)$ is Pareto with a coefficient of 5 and in setting the elasticity of substitution to $\sigma=3$. As in Eaton et al. (2011), we assume that the distribution of $\chi_{j i}$ for each $i$ is $\log$ normal and we arbitrarily set the parameters of the distribution to 0 and 1. Finally, we assume that $\log (f)$ is distributed normally across firms with mean 0 and standard deviation 0.25 and set $\bar{s}=2$ and $\underline{s}=1$. We conduct these simulations for the case of 5 export markets and show that — keeping firms which always export and with a Herfindahl below one - the regression of volatility on size, Herfindahl and their interaction gives qualitatively similar results to the ones we observe. This confirms that the mechanisms of our model generate similar results for the case of more countries under reasonable assumptions. Detailed results and codes are available from the authors upon request.

\section{A.1.5 Allowing for a positive correlation of shocks between markets}

We here show that our results extend to the case where shocks are positively (but imperfectly) correlated between markets. Define $\alpha / 2$ as the probability that both shocks are high ( $\bar{s}$ on both markets). Since the unconditional probabilities of good and bad shocks are $1 / 2$ on both markets, the probability that both shocks are low is also equal to $\alpha / 2$, while the probability of having $\underline{s}$ on market $i$ and $\bar{s}$ on market $i^{\prime}$ is equal to $(1-\alpha) / 2 . \alpha \geq 1 / 2$ indexes the degree to which shocks between the two markets are positively correlated ( $\alpha=1 / 2$ corresponds to zero correlation). With a covariance between shocks, the right hand side of (25) now has an additional component equal to $E\left[\omega_{j 1 t} g_{j 1 t} \omega_{j 2 t} g_{j 2 t}\right]$. If firm $j$ exports continuously to both markets, the covariance of its growth rates on markets 1 and 2 is:

$$
\operatorname{Cov}_{j 12}^{C}=2 \mu(2 \alpha-1)
$$

while the covariance of its sales if it exports occasionally to one of the markets is:

$$
\operatorname{Cov}_{j 12}^{O}=2 \sqrt{\mu}(2 \alpha-1) \text {. }
$$

The volatility of export growth can now be approximated by the following expression:

$$
V_{j}=\omega_{j 1}^{2} V A R_{j 1}+\omega_{j 2}^{2} V A R_{j 2}+2 \omega_{j 1} \omega_{j 2} \operatorname{Cov}_{j 12},
$$

where solving (12) for $\omega_{j}$ easily shows that:

$$
\omega_{j 1} \omega_{j 2}=\frac{1-\operatorname{Herf}_{j}}{2}
$$


The derivative of the volatility with respect to the Herfindahl index simply becomes:

$$
\begin{aligned}
\frac{\mathrm{d} V_{j}^{C}}{\mathrm{dHerf}} & =2 \mu-\operatorname{Cov}_{j 12}^{C}=4 \mu(1-\alpha), \\
\frac{\mathrm{d} V_{j}^{O}}{\mathrm{dHerf} f_{j}} & =1+\mu-\frac{1-\mu}{\sqrt{2 \operatorname{Herf} f_{j}-1}}-\operatorname{Cov}_{j 12}^{O} \\
& =4 \mu(1-\alpha) \underbrace{-(1-\mu)\left(\frac{1}{\sqrt{2 H e r f_{j}-1}}-1\right)-2 \sqrt{\mu}(2 \alpha-1)(1-\sqrt{\mu})}_{<0} .
\end{aligned}
$$

Therefore: $\mathrm{d} V_{j}^{O} / \mathrm{d} H \operatorname{erf} f_{j}<\mathrm{d} V_{j}^{C} / \mathrm{d} H \operatorname{erf} f_{j}$ if $\alpha \geq 1 / 2$. For $\operatorname{Herf}_{j}$ sufficiently small, the effect of the Herfindahl index on the volatility of exports again turns negative among occasional exporters.

\section{A.2 Data appendix}

Export value and domestic sales used in this research are deflated using GDP deflator based on the price of the year 2000. The country-level data are from World Bank Development Indicators maintained by the World Bank. We use GDP per capita (in US dollars) in 2003 as the measure of the income levels of countries. Destination market volatility is measured as the variance of the growth in the country's real GDP. The firm-level variables of destination income and destination volatility are constructed as the weighted averages of the destinations' income and volatility respectively with the weights being the destinations' shares in the firm's total export sales. Product volatility is defined as the average annual growth rate of the export sales of HS6 (1996 version) products. Similar to the above firm-level measures, firm-level product volatility is defined as the weighted average of the volatility of products a firm exports with the weights being the products' shares in the firm's total export sales.

Throughout our regression analysis for both the CCTS and the matched CCTS-ASIF samples, we exclude the $1 \%$ observations with the highest volatility to minimize the effect of outliers on our results. However, we also tried keeping all observations in the regression samples, and the differences in estimates are minimal.

\section{A.3 Additional figures and tables}




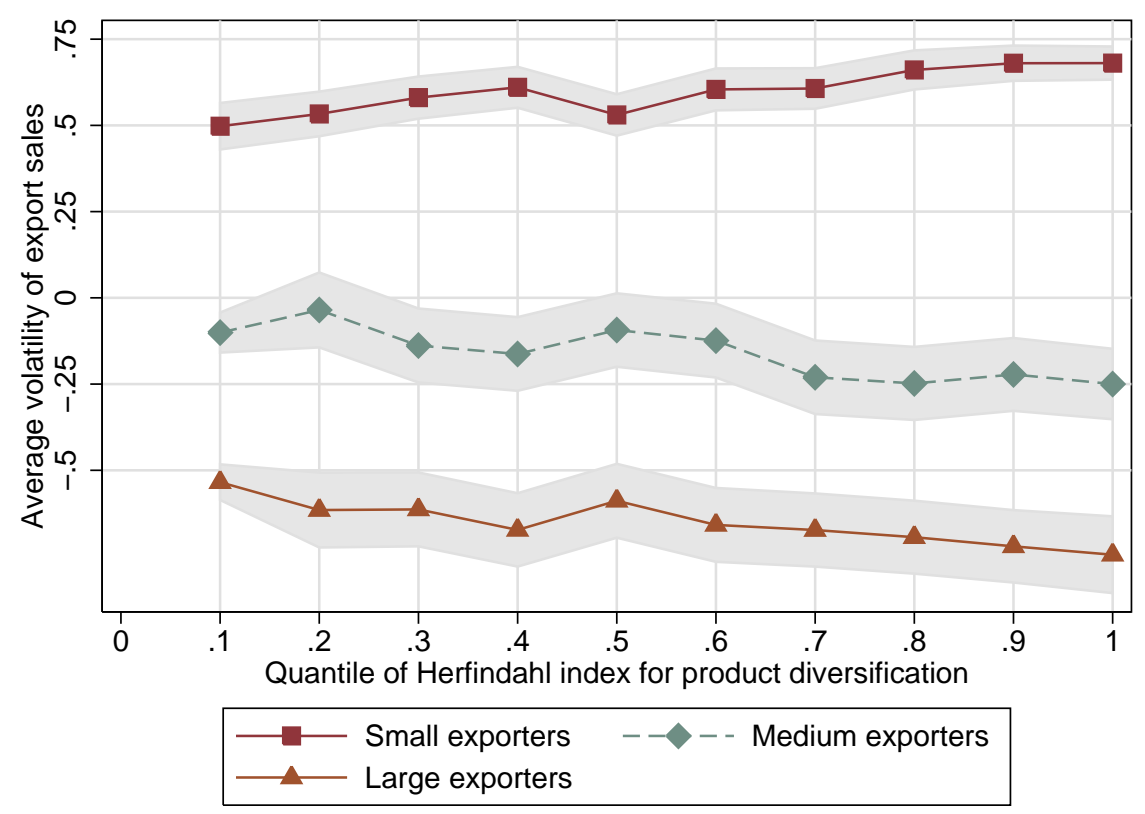

Figure A2. Volatility and product diversification. Export volatility is measured as log of squared deviation in export growth rate from firm's own average. Quantiles of Herfindahl index is defined on the whole population of firms. Firm size category is defined according to the firm's exports (averaged over years) relative to the tertiles of its corresponding industry-province-ownership cell. Volatility and Herfindahl index are removed of industry, province, and ownership effects. Source: CCTS.

Table A1. Volatility of firm-destination-level exports

Dependent variable: volatility of export sales at firm-destination level. Sample: CCTS.

\begin{tabular}{|c|c|c|c|c|c|}
\hline & (1) & (2) & (3) & (4) & (5) \\
\hline Exports (firm-dest level) & $\begin{array}{l}-0.182 * * * \\
(0.000)\end{array}$ & $\begin{array}{l}-0.132 * * * \\
(0.000)\end{array}$ & $\begin{array}{l}-0.143 * * * \\
(0.000)\end{array}$ & $\begin{array}{l}-0.137 * * * \\
(0.000)\end{array}$ & $\begin{array}{l}-0.151 * * * \\
(0.000)\end{array}$ \\
\hline Num of years of exporting (firm-dest level) & & $\begin{array}{l}-0.118 * * * \\
(0.000)\end{array}$ & $\begin{array}{l}-0.106^{* * * *} \\
(0.000)\end{array}$ & $\begin{array}{l}-0.098 * * * \\
(0.000)\end{array}$ & $\begin{array}{l}-0.076 * * * \\
(0.000)\end{array}$ \\
\hline Exports (firm level) & & & $\begin{array}{l}0.001 * \\
(0.000)\end{array}$ & $\begin{array}{l}-0.005^{* * * *} \\
(0.000)\end{array}$ & \\
\hline Prov-ind-own dummies & No & No & Yes & Yes & No \\
\hline Destination dummies & No & No & No & Yes & Yes \\
\hline Firm fixed effects & No & No & No & No & Yes \\
\hline \# Observations & $1,434,041$ & $1,434,041$ & $1,434,041$ & $1,434,041$ & $1,434,041$ \\
\hline R-squared & 0.204 & 0.257 & 0.300 & 0.316 & 0.458 \\
\hline
\end{tabular}

Note. This table reports the regression results of firm-destination-level export volatility. The dependent variable is export volatility defined at firm-destination level. All other variables are defined as in the previous tables. Robust standard errors are in parentheses, and superscripts *, **, $* * *$ indicate significance at $10 \%, 5 \%$, and $1 \%$ levels respectively. 
Table A2. Destination-product diversification and volatility

Dependent variable: volatility of export sales. Samples: CCTS and matched CCTS-ASIF.

\begin{tabular}{|c|c|c|c|c|c|c|}
\hline & \multicolumn{3}{|c|}{ CCTS sample } & \multicolumn{3}{|c|}{ Matched CCTS-ASIF sample } \\
\hline & (1) & $(2)$ & (3) & (4) & $(5)$ & (6) \\
\hline Herfindahl_dest_prod & $\begin{array}{l}-0.447 * * * \\
(0.150)\end{array}$ & $\begin{array}{l}-0.744 * * * \\
(0.153)\end{array}$ & $\begin{array}{l}-0.674 * * * \\
(0.151)\end{array}$ & $\begin{array}{l}-1.738 * * * \\
(0.464)\end{array}$ & $\begin{array}{l}-1.721 * * * \\
(0.463)\end{array}$ & $\begin{array}{l}-1.647 * * * \\
(0.460)\end{array}$ \\
\hline Exports & $\begin{array}{l}-0.308 * * * \\
(0.008)\end{array}$ & $\begin{array}{l}-0.285^{* * *} \\
(0.008)\end{array}$ & $\begin{array}{l}-0.279 * * * \\
(0.008)\end{array}$ & $\begin{array}{l}-0.450 * * * \\
(0.022)\end{array}$ & $\begin{array}{l}-0.422 * * * \\
(0.023)\end{array}$ & $\begin{array}{l}-0.411 \text { *** } \\
(0.022)\end{array}$ \\
\hline Herfindahl_dest_prod $\times$ Exports & $\begin{array}{l}0.037 * * * \\
(0.011)\end{array}$ & $\begin{array}{l}0.062 * * * \\
(0.011)\end{array}$ & $\begin{array}{l}0.057 * * * \\
(0.011)\end{array}$ & $\begin{array}{l}0.111 * * * \\
(0.029)\end{array}$ & $\begin{array}{l}0.112 * * * \\
(0.028)\end{array}$ & $\begin{array}{l}0.107 * * * \\
(0.028)\end{array}$ \\
\hline Log sales & & & & $\begin{array}{l}0.188 * * * \\
(0.019)\end{array}$ & $\begin{array}{l}0.169 * * * \\
(0.020)\end{array}$ & $\begin{array}{l}0.179 * * * \\
(0.020)\end{array}$ \\
\hline Log age & & & & $\begin{array}{l}-0.075 * * * \\
(0.025)\end{array}$ & $\begin{array}{l}-0.065 * * * \\
(0.025)\end{array}$ & $\begin{array}{l}-0.064 * * * \\
(0.025)\end{array}$ \\
\hline Log wage & & & & $\begin{array}{l}-0.049 * \\
(0.026)\end{array}$ & $\begin{array}{l}-0.047 * \\
(0.026)\end{array}$ & $\begin{array}{l}-0.044 * \\
(0.026)\end{array}$ \\
\hline Log capital intensity & & & & $\begin{array}{l}0.025 \\
(0.015)\end{array}$ & $\begin{array}{l}0.022 \\
(0.015)\end{array}$ & $\begin{array}{l}0.022 \\
(0.015)\end{array}$ \\
\hline Leverage ratio & & & & $\begin{array}{l}0.275 * * * \\
(0.061)\end{array}$ & $\begin{array}{l}0.260 * * * \\
(0.060)\end{array}$ & $\begin{array}{l}0.262 * * * \\
(0.060)\end{array}$ \\
\hline Income of destinations & & $\begin{array}{l}-0.115^{* * * *} \\
(0.016)\end{array}$ & $\begin{array}{l}-0.118^{* * *} \\
(0.016)\end{array}$ & & $\begin{array}{l}-0.097 * * \\
(0.039)\end{array}$ & $\begin{array}{l}-0.106 * * * \\
(0.039)\end{array}$ \\
\hline Volatility of destinations & & $\begin{array}{l}0.049 * * * \\
(0.010)\end{array}$ & $\begin{array}{l}0.050 * * * \\
(0.010)\end{array}$ & & $\begin{array}{l}0.064 * * * \\
(0.023)\end{array}$ & $\begin{array}{l}0.066^{* * * *} \\
(0.023)\end{array}$ \\
\hline Avg exp growth rate & & $\begin{array}{l}0.912 * * * \\
(0.049)\end{array}$ & $\begin{array}{l}0.943^{* * *} * \\
(0.049)\end{array}$ & & $\begin{array}{l}0.375 * * * \\
(0.128)\end{array}$ & $\begin{array}{l}0.545^{* * *} * \\
(0.130)\end{array}$ \\
\hline Volatility of products & & & $\begin{array}{l}0.118 \\
(0.087)\end{array}$ & & & $\begin{array}{l}0.051 \\
(0.211)\end{array}$ \\
\hline Change in num of dest-prod pairs & & & $\begin{array}{l}-0.001 * * * \\
(0.000)\end{array}$ & & & $\begin{array}{l}-0.003^{* * * *} \\
(0.000)\end{array}$ \\
\hline Prov-ind-own dummies & Yes & Yes & Yes & Yes & Yes & Yes \\
\hline \# Observations & 23,584 & 23,581 & 23,581 & 8,268 & 8,268 & 8,268 \\
\hline R-squared & 0.335 & 0.350 & 0.354 & 0.574 & 0.577 & 0.582 \\
\hline
\end{tabular}

Note. This table reports results of destination-product diversification and export volatility. The dependent variable is export volatility. Herfindahl_dest_prod is the the sum of the squared shares of sales for each destination-product pair in the initial year. A new variable included is the change in the number of destination-product pairs. All other variables are defined as in the previous tables. Robust standard errors are in parentheses, and superscripts $*, * *, * * *$ indicate significance at $10 \%, 5 \%$, and $1 \%$ levels respectively. 


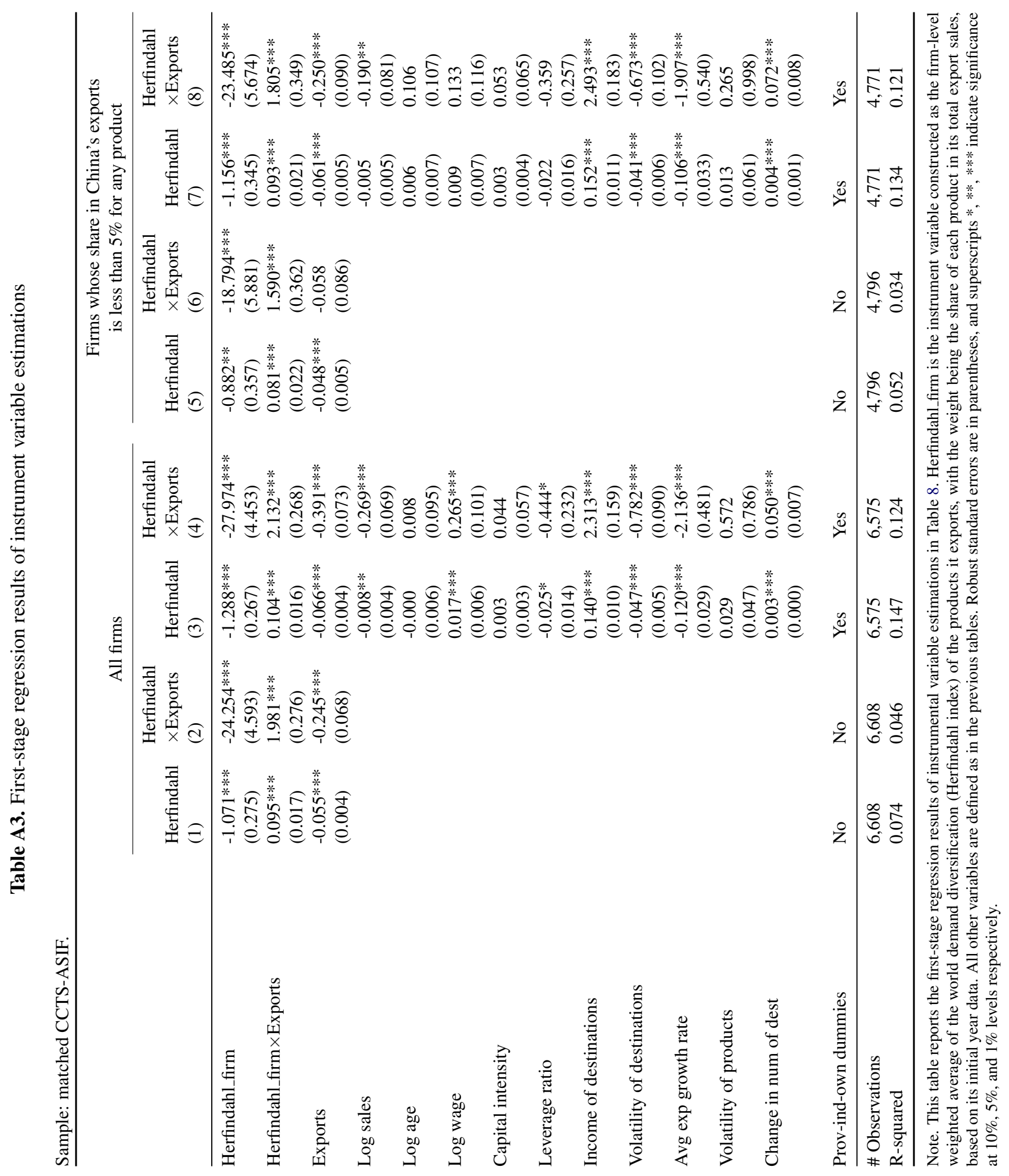




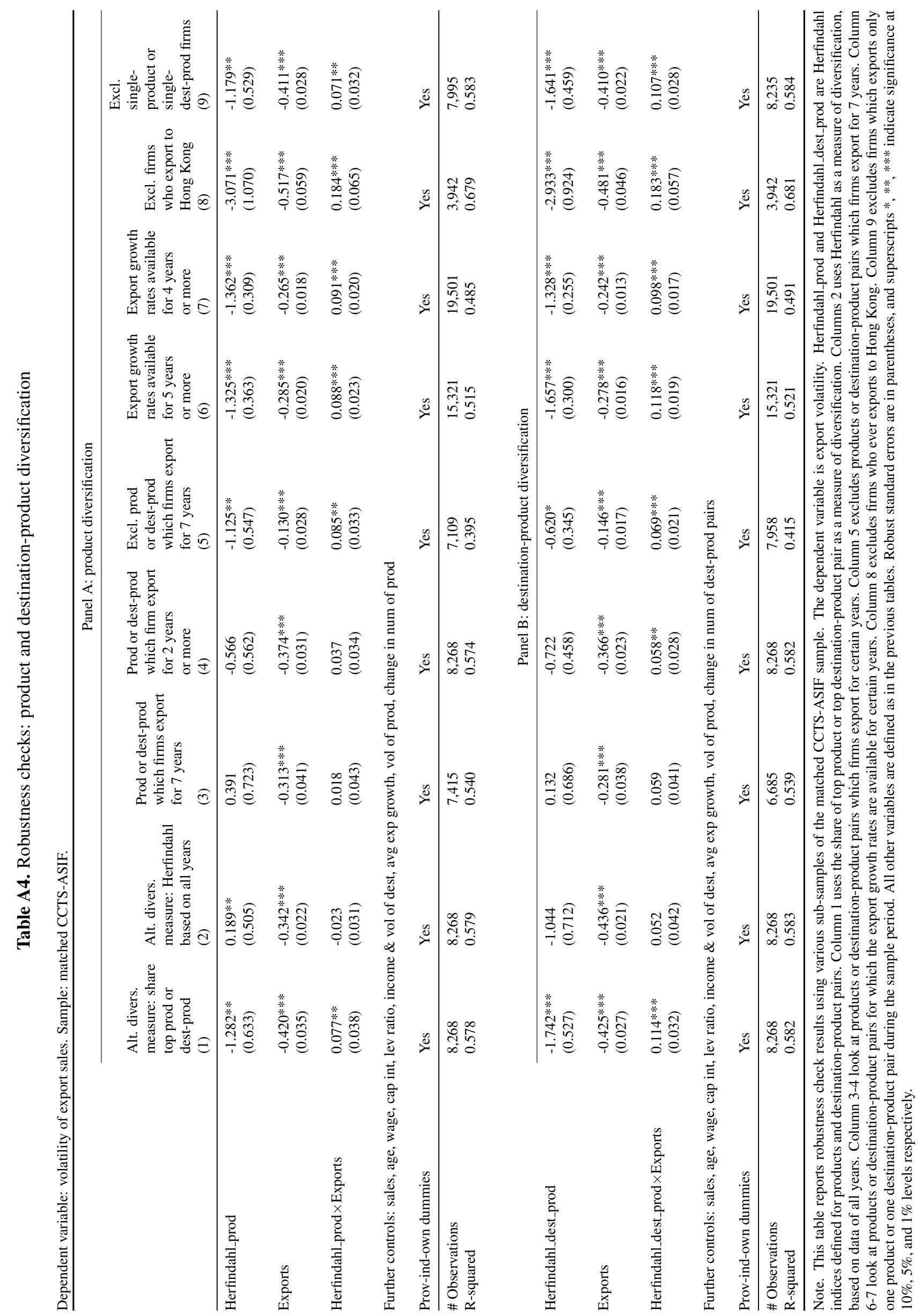

